\title{
NMDAr BLOCKING BY MK801 ALTERS HIPPOCAMPAL AND PREFRONTAL CORTEX OSCILLATIONS AND IMPAIRS SPATIAL WORKING MEMORY IN MICE.
}

\author{
P. Abad-Perez ${ }^{1.2}$; L. Martínez-Otero², V. Borrell2; R. Redondo³, J.R. Brotons- \\ $\operatorname{Mas}^{* 1,2}$
}

1 Universidad Cardenal Herrera CEU, Elche

2 Instituto de Neurociencias UMH-CSIC. Alicante

3 Roche Pharma Research and Early Development, Neuroscience and Rare Diseases, Roche Innovation Center Basel

${ }^{*}$ Corresponding author

Jorge R Brotons-Mas

e-mail: Jorge.brotonsmas@chceu.es

Address: Universidad CEU Cardenal Herrera; Plaza Reyes Católicos, 19. 03204 Elche - Alicante, Spain

Instituto de Neurocienicas UMH-CSIC; Avd Ramón y Cajal SN, Edificio Ramón y Cajal, 03550,San Juan de Alicante, Alicante, Spain.

Tel. +34965426486

\section{Declaration of interest}

The authors declare that they have no known competing financial interests or personal relationships that could have appeared to influence the work reported in this paper. 


\section{Abstract}

Abnormal NMDAr function has been linked to rhythmopathies, psychosis, and cognitive dysfunction in schizophrenia. Here, we investigate the role of NMDAr hypofunction in pathological oscillations and behavior. We implanted mice with tetrodes in the dorsal hippocampus and medial prefrontal cortex (mPFC) and administered them with the NMDAr antagonist MK801, recording oscillations during spontaneous exploration in an open field and in the $y$-maze spatial working memory test. Our results show that NMDAr blockade increased locomotor activity and impaired spatial working memory. The administration of MK801 disrupted the correlation between oscillations and speed of movement, crucial for internal representations of distance. In the hippocampus, MK801 impaired gamma oscillations and theta/gamma coupling, while in the MPFC, it increased the power of theta, gamma, and generated high-frequency oscillations (HFO 155-185 $\mathrm{Hz}$ ). Spatial working memory tests in the y-maze revealed that theta/gamma coupling was consistently higher in correct trials. Theta/gamma co-modulation mediated by NMDAr function might be key to explain various of schizophrenia's cognitive symptoms. Further investigating NMDAr hypofunction's role in the emergence of aberrant oscillatory activity will improve our understanding of schizophrenia and inspire new treatments of psychiatric disorders.

Keywords: Schizophrenia, oscillatory activity, hippocampus, prefrontal cortex, NMDAr.

\section{Highlights:}

- NMDAr blockade increases motor behavior and impairs spatial working memory.

- NMDAr hypofunction differentially alters oscillatory activity in the hippocampus and PFC.

- NMDAr blockade generates locally modulated high-frequency oscillations in the PFC.

- Theta/gamma modulation, but also long-range theta/gamma modulation across CA1 and the PFC is involved in spatial working memory.

- NMDAr blockade disrupts the correlation between theta/gamma co-modulation and spatial working memory performances. 


\section{Introduction}

Schizophrenia is a disabling disease characterized by negative, positive, and cognitive symptoms e.g., lack of social interest, psychosis, working memory deficits (Owen et al., 2016). A dominant theory about schizophrenia's etiology is the dopaminergic hypothesis, which posits that the disorder is caused by dopamine imbalance and is supported by the therapeutic effects of anti-dopaminergic drugs (Ban, 2007; Meltzer \& Stahl, 1976). However, neuroleptic medications fail to treat negative and cognitive symptoms, suggesting that multiple mechanisms are at play in the generation of schizophrenia's symptoms (Harvey et al., 2006; James et al., 2018; Kirkpatrick et al., 2006). The NMDAr hypofunction hypothesis of schizophrenia may offer a complementary explanation of the etiology of this disorder, including its cognitive symptoms. NMDAr antagonists can induce schizophrenia-like symptoms in patients and healthy subjects (Adler et al., 1998; Malhotra et al., 1997). Schizophrenic patients showed a reduced expression of NMDAr in the dorsolateral prefrontal cortex (DLPFC), a brain region strongly involved in working memory and executive function, generally impaired in schizophrenia (Beneyto \& MeadorWoodruff, 2008; C. S. Weickert et al., 2013). NMDAr loss of function seems to dysregulate dopamine levels (indirectly increasing striatal dopamine levels), linking NMDAr function with the previously observed dopamine imbalance (Del Arco et al., 2008; Vollenweider et al., 2000; Wędzony et al., 1993). Additionally, animal models of schizophrenia based on NMDAr hypofunction successfully mimic the positive, negative, and cognitive symptoms as well as structural brain changes observed in schizophrenic patients (Abekawa et al., 2007; Eyjolfsson et al., 2006; Jodo, 2013; López-Gil et al., 2007; Murueta-Goyena Larrañaga et al., 2017; Olney et al., 1999). Finally, the pharmacological blockade of NMDAr produces not only cognitive symptoms similar to 
those seen in schizophrenia but also its associated aberrant oscillatory activity and interneuron dysfunction (Hakami et al., 2009; Hertzman et al., 1990; James et al., 2018; Kristiansen et al., 2006; Lewis, 2012).

NMDAr hypofunction is thought to primarily act in schizophrenia on PV+ inhibitory interneurons, decreasing their activity. Indeed, the deletion of NMDAr from parvalbuminpositive interneurons $\left(\mathrm{PV}^{+}\right)$in mice triggers cognitive symptoms recapitulating many of those observed in humans (Belforte et al., 2010; Braff et al., 2001; Korotkova et al., 2010; Mena et al., 2016; Weickert et al., 2000). At the cellular level, NMDAr hypofunction induced by MK801 administration reduces the firing of GABAergic interneurons, which in return increases the firing rate of excitatory pyramidal neurons (Homayoun \& Moghaddam, 2007; Jackson et al., 2004). Therefore, the NMDAr hypofunction hypothesis offers a possible mechanism that links the cognitive deficits, the aberrant oscillatory activity, and the interneuron dysfunction observed in schizophrenia, while at least partially explaining some of the dopamine changes typically observed in patients (Lewis, 2012; Moghaddam \& Javitt, 2012; Uhlhaas \& Singer, 2010)

Despite the accumulation of data regarding the role of NMDAr hypofunction at the level of cellular and synaptic mechanisms, its relationship to cognition remains poorly understood. Dizocilpine, or MK801, is an NMDAr antagonist that acts by noncompetitively blocking NMDAr's voltage-dependent ion channels (Huettner \& Bean, 1988). It is commonly used as a model of schizophrenia in rodents as it reproduces its cognitive deficits, gamma power alterations, and the emergence of high-frequency oscillations (HFO) across different brain regions (Adell et al., 2012; Lee et al., 2017).

Here, we aim to understand how NMDAr blockade by MK801 can affect oscillatory activity, behavior, cognition, and the dialog between the hippocampus CA1 and prefrontal cortex (PFC). These hippocampal regions are connected directly and indirectly with the PFC (Hoover \& Vertes, 2007) and their interaction is critical for executive 


\section{Abad et al}

function and schizophrenia (Jones \& Wilson, 2005; Sigurdsson \& Duvarci, 2016). We were especially interested in determining the oscillatory correlates involved in spatial cognition and decision-making in spatial working memory. For this reason, we recorded simultaneously from the intermediate CA1 and the PFC and investigated the effect of MK801-mediated NMDAr blockade in oscillatory activity, behavior, and spatial working memory performance. Our results indicated that NMDAr blockade impaired spatial working memory, generated area-specific changes in the hippocampus and the PFC, and altered the relationship between oscillatory activity and motor behavior. 


\section{Methods}

\section{Subjects}

Male wild type mice $\mathrm{C} 57, \mathrm{~N}=9$, age p60 to p90 supplied by the UMH Servicio de Experimentación Animal (SEA) were used. Mice were maintained on a $12 \mathrm{~h}$ light/dark cycle with food and water available ad libitum and were individually housed after electrode implantation. Our procedures were approved by the UMH-CSIC ethics committee and met local and European guidelines for animal experimentation (86/609/EEC).

\section{In vivo recordings on freely moving mice}

Microdrives, (Axona Itd) mounting four tetrodes (12 $\mu \mathrm{m}$ tungsten wire, California Fine Wire Company, Grover Beach, CA, USA) were implanted under isoflurane anesthesia $(1.5 \%)$ while buprenorphine $(0.05 \mathrm{mg} / \mathrm{kg}$, s.c.) was supplied as analgesia. Craniotomies were performed above the hippocampus and medial prefrontal cortex (mPFC), targeting the hippocampal CA1 region (AP: -2-2.5, M-L:1.2 V: $0.6 \mathrm{~mm}$ ) as well as the prelimbic region of the mPFC (AP: 1-2, M-L:0.5-1, V: 1.2-1.9 mm).

\section{Data acquisition.}

Electrophysiological recordings were obtained using a 16-channel headstage (Axona Ltd, UK). (gain $\times 1$ ), with an infrared light-emitting diode (LED) to track mouse position (J. R. Brotons-Mas et al., 2010; J. R. R. Brotons-Mas et al., 2017; delPino et al., 2013). Signals were amplified (400 to $1000 \mathrm{x}$ ), bandpass filtered $(0.3 \mathrm{~Hz}$ to $24 \mathrm{KHz}$, DacqUSB system, Axona, UK) and recorded at $48 \mathrm{KHz} / 24$-bit precision. For Local field potential recordings (LFP), tetrodes were lowered to reach specific stereotaxic coordinates in the mPFC. Unit activity, ripples (high-frequency events $1500-200 \mathrm{~Hz}$ ), and theta power were used as electrophysiological landmarks to determine electrode location in the CA1 pyramidal layer. Once tetrodes were located in the target areas, we started our recording protocols.

\section{Power spectrum analysis}

Local field potentials were analyzed using custom-written MatLab codes (Mathworks, Natick, MA, USA). Raw recordings were FIR filtered $(<1.2 \mathrm{KHz})$ and downsampled to 2.4 $\mathrm{KHz}$, as in previous work (del Pino et al., 2017). Data obtained in open field recordings was used to characterize the local field potential. Running speed was computed based on the animal's position. Epochs of behavior in which the speed of movement was above $5 \mathrm{~cm} / \mathrm{s}$ were included for analysis. In this way, we obtained similar behavioral episodes 
across the different conditions. To visualize the power spectrum, the spectral power (in decibels 10log10) and spectrogram was built using the Thomson multi-taper method included in Chronux (Bokil et al., 2010). A notch filter $(50 \mathrm{~Hz})$ was implemented to eliminate electrical noise. Also, high-frequency noise $(135-145 \mathrm{~Hz})$ associated with chewing artifacts and some motor behaviors were observed in the periodogram. Therefore, to eliminate this noise, we did include for analysis this band. The functional connectivity between the hippocampus and the prefrontal cortex was measured by calculating frequency coherence. This measurement describes the degree of cooccurrence of different frequencies in the activity recorded across different areas. The different bands' coherence was calculated as the summatory of all coherence values between the critical bands and expressed as arbitrary units (a.u.).

( [C,phi,S12,S1,S2,t,f,confC,phistd,Cerr]=cohgramc(data1, data2, movingwin,params) )

For LFP analysis, we segmented the signal in non-overlapping windows of $1 \mathrm{~s}$. Then, we calculated the power spectrum and obtained the theta/delta ratio to eliminate epochs contaminated by mechanical artifacts. Finally, we calculated the power spectrum for theta and low and high gamma bands and calculated the speed of movement for each epoch to establish the possible correlation between oscillatory activity and movement speed. We calculated theta and gamma activity power for epochs in which locomotor activity was not present. We also performed a bipolar derivation, subtracting the signal obtained from two channels in different tetrodes implanted in the PFC. This approach should control for possible volume propagation from adjacent brain areas.

\section{Gamma modulation index (GMI)}

The gamma modulation index was calculated as previously described (Korotkova et al., 2010). In brief, the raw LFP was filtered in the theta band $(4-12 \mathrm{~Hz})$ and in different higher frequency intervals: low gamma (30-65 Hz), high gamma (66-130), and high-frequency oscillations (155-185 Hz). The gamma and HFO envelopes were then calculated to determine the power of the signal across the different theta cycles; the maximum and minimum values were used to calculate an index of modulation.

$\mathrm{GMI}=(\max -\min ) /(\max +\min )$.

\section{Drug administration and dose}

Before drug administration, a baseline recording was obtained. This condition served as a baseline to calculate ratios of change for each condition. Mice were then injected subcutaneously with MK801 $(0.075 \mathrm{mg} / \mathrm{kg})$ or with the vehicle solution. Recordings were 
initiated at the peak of drug bioavailability, $15 \mathrm{~min}$ after injection. Drugs were administered following a counterbalanced scheme across alternate days, spacing the recordings at least $48 \mathrm{~h}$ to ensure that the drugs were fully metabolized.

\section{Behavioral Protocol}

Recordings were performed in the animal's homes for several minutes to ensure that the electrodes were placed in the CA1 pyramidal layer. Recordings were then performed during spontaneous exploration in an open field of $50 \times 50 \mathrm{~cm}$. The animals were subsequently left to rest for five minutes in their home cage before 8 minutes of $y$-maze testing. After the last $y$-maze trial, mice were recorded in their home cage. The drug or vehicle was administered, and the process started again.

\section{Working memory in the y-maze}

We used the y-maze to measure working memory. Testing was carried out on a transparent $Y$-shaped maze $(40 \times 10 \mathrm{~cm}$ per arm). Mice were placed at the end of the central arm and allowed to freely explore the maze for $8 \mathrm{~min}$. The sequence of arm entries was obtained from the $x, y$ position coordinates and automatically analyzed using custom-made scripts in MATLAB. Correct alternations were those in which the animal visited an arm not visited recently, e.g., visit sequence: arm 1-2-3. We considered incorrect alternations when animals repeated the same arm in a sequence of trials, e.g. arm 1-2-1. The final score was calculated as the percentage of correct triads using the formula below:

Spontaneous alternation $\%=\frac{\# \text { spontaneous alternations }}{\text { total number of arm entries }-2} \times 100$

We searched for different electrophysiological biomarkers of spatial working memory to investigate normal and pathological mechanisms during memory performance in the $y$ maze. To this end, we analysed LFP epochs of 1s duration, half a second before the mice entered the decision area of the $y$-maze (the central triangle between the three arms) and half a second later. We only included experiments consisting of at least nine entries in the different arms in one of the conditions, baseline or drug. This ensured the sampling of a minimum of LFP epochs. As animals explore much less in the vehicle condition, we center our analysis on the baseline-MK801 conditions, focusing the LFP obtained in these sets of experiments and including $\mathrm{N}=7$ mice.

\section{Anatomical verification of electrode location}

After completing experiments, animals were deeply anesthetized using sodium pentobarbital (Euthanasol, $1 \mathrm{~mL} / \mathrm{kg}$, i.p.) and transcardially perfused with saline and $4 \%$ paraformaldehyde; the brains were removed, sliced in $40 \mu \mathrm{m}$ sections, and prepared for 
Immunohistochemistry against DAPI, NeuN (Merck,Itd) and GFAP (Adigene technologies) for electrode localization.

A

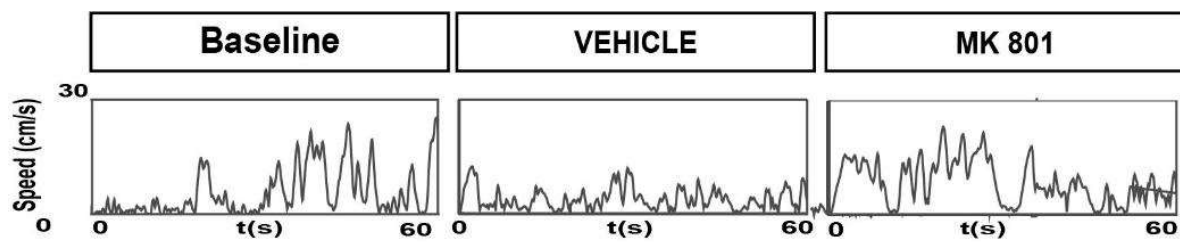

B
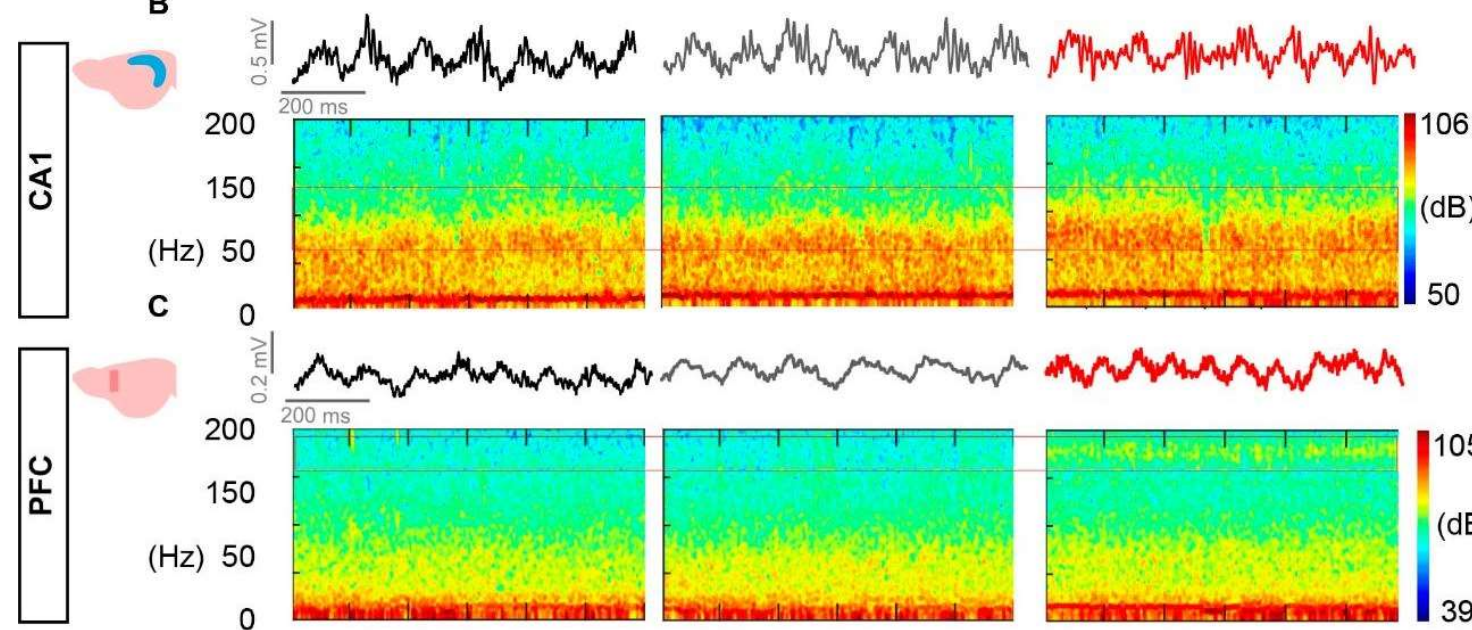

늠
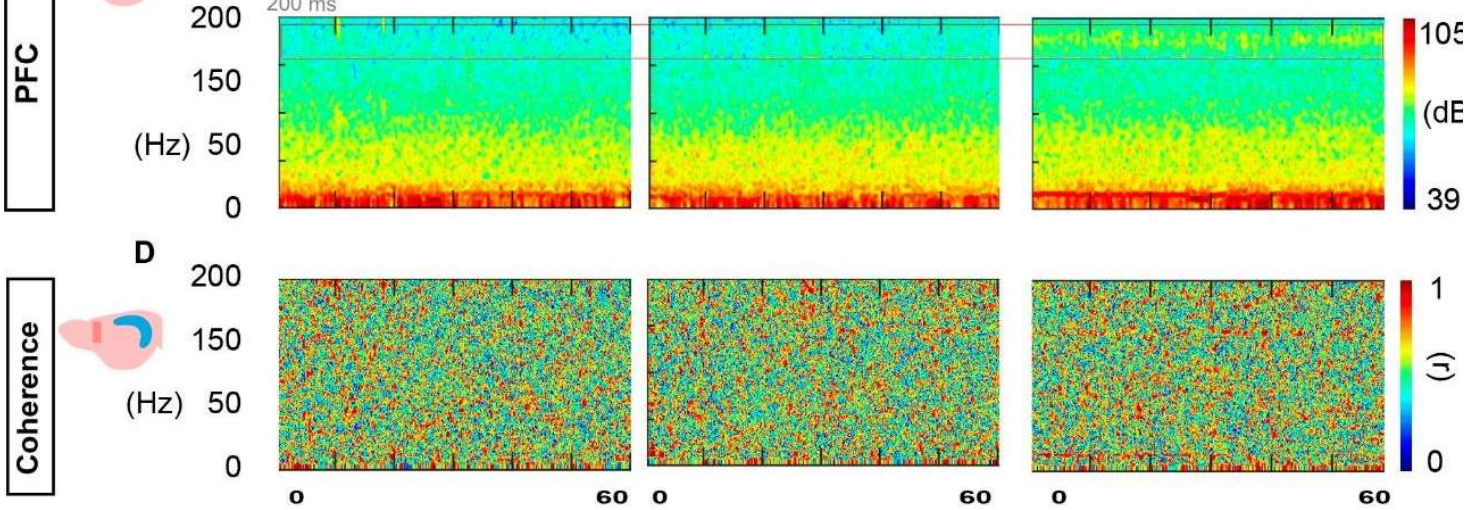

Figure 1. Freely moving recordings. Mice were implanted with tetrodes in the hippocampus CA1 and the PFC. Recordings were performed during freely moving exploration in an open field. Sessions consisted of a 900s baseline recording followed by a second recording performed after the administration of vehicle or MK801. The position and the speed of movement were monitored (A). Spectrograms and power coherence were calculated for each session B, C, D. Note the increases in gamma activity in CA1 and the appearance of HFO) (155$185 \mathrm{~Hz}$ ) in the prefrontal cortex, (red squares) and increase in speed during the MK801 condition. 


\section{Results}

We aimed to determine the effects of NMDAr blockade on PFC and HC oscillatory activity and spatial working memory. Our results indicated that NMDAr blockade generated areaspecific changes in the hippocampus and the PFC and altered the relationship between oscillatory activity and motor behavior. We observed that theta-gamma modulation was consistently higher during correct trials in the y-maze.

\section{Behavioral effects of MK801}

First, we characterized the activity of mice in the baseline vs. vehicle experiment. We found that animals presented higher levels of activity during the baseline vs. the vehicle condition. This was probed through a set of variables including speed of movement, total distance run and immobility time (mean $\pm s e$, baseline vs vehicle, $\mathrm{m} / \mathrm{s}, 0.04 \pm 0.006$ vs $0.03 \pm 0.004 ; \mathrm{t}_{(8)}=4.39, \mathrm{p}<0.01$, distance $(m), .45 .22 \pm 7.5$ vs $30.51 \pm 11.4 ; \mathrm{t}_{(8)}=3.39, \mathrm{p}<0.01$, $\%$ time, 48.32 $\pm 64.45 ; \mathrm{t}_{(8)}=-5.5 .3, \mathrm{p}<0.001$ ), see Fig 2 .

Then, we sought to evaluate whether significant changes in locomotor behavior were produced after NMDAr blockade. Exploratory and locomotor activity was increased after MK801 administration, as revealed by the mean speed, total distance run and immobility time ( $\operatorname{speed}(\mathrm{m} / \mathrm{s}), 0.04 \pm 0.003$ vs $0.11 \pm 0.009 ; \mathrm{t}_{(8)}=-8.6, \mathrm{p}>0.001$, distance $(\mathrm{m}), 47.1 \pm 7.5$ vs $107.6 \pm 5.4 ; \mathrm{t}_{(8)}=-7.56 \mathrm{p}>0.001, \%$ time, $49.03 \pm 4.11$ vs $13.39 \pm 2.15 ; \mathrm{t}_{(8)}=8.31$, $\mathrm{p}>0.001)$.

Anxious animals normally spend more time in the periphery and delay or cancel their visits to the center of the open field, therefore to evaluate potential changes in anxietyrelated behavior, we measured the latency to visit the center of the open field The latency to visit the open field's center was significantly different between the vehicle and the MK801 condition but not between the rest of the conditions (baseline vs vehicle, $83.84 \pm 51.7$ vs $213.2 \pm 62.5, z=-1.955, p>0.05$, baseline vs $m k 801,87.49 \pm 47.98$ vs $17.18 \pm 8.51, z=-1.955, p>0.05$ vehicle vs Mk801, latency $(s), z=2.521, p<0.05)$, see Fig $2 \mathrm{E}$.

We looked for further differences between the vehicle and MK801 conditions, and observed significant differences in speed, total distance run and immobility time, further showing the augmented exploratory behavior after MK801 administration $\left(m / s ; t_{(8)}=8.9\right.$, $\mathrm{p}>0.001$, distance $(m), \mathrm{t}_{(8)}=7.19, \mathrm{p}>0.001, \%$ time $\left., \mathrm{t}_{(8)}=-9.19, \mathrm{p}>0.001\right)$. All significant 
differences were maintained after Bonferroni corrections (to account for the number of comparisons) for $p<0.05$.

NMDAr blocking by MK801 administration reliably increased locomotor activity in mice during open field spontaneous exploration.

\section{Exploration and locomotor behavior}

A

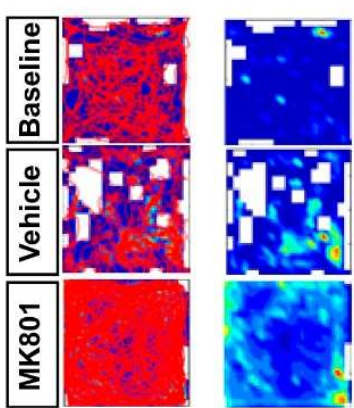

D

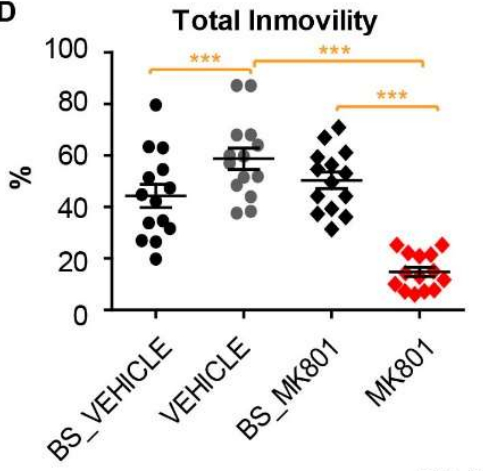

B

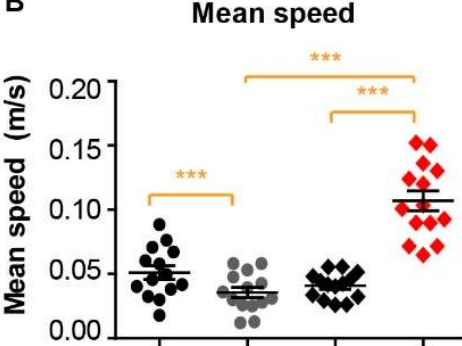

E

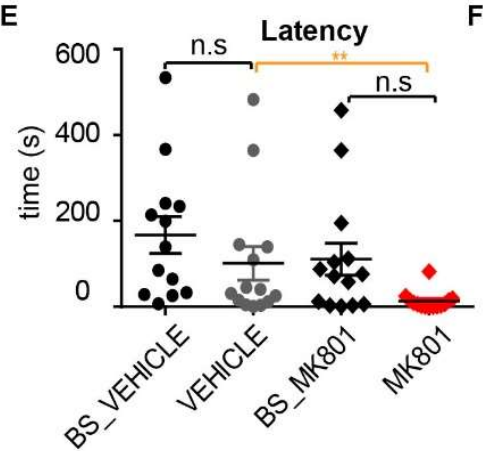

C

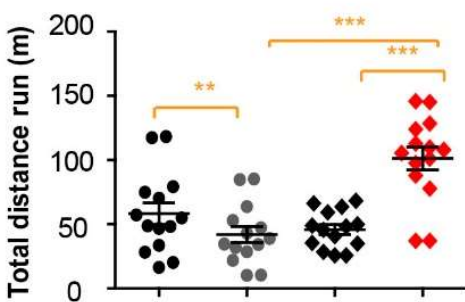

Speed Probability

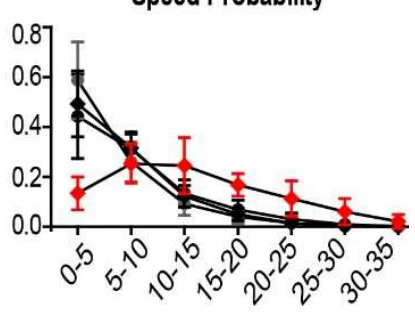

Figure 2. MK801 increased exploration and locomotor behavior. A. Representative tracking and dwelling time maps in the open field for the baseline, vehicle, and MK801 condition, note the track covering almost all coordinates of the open field. B. Mean speed. C. Total distance run. D. Total immobility time. E. Latency to visit the center of the open field. F. Probability of occurrence of different speed intervals. Note the lower probability of low speed and the higher probability of higher speeds after MK801 administration. Also, note the similarity of behavioral parameters for the different baseline conditions across different days. 
MK801 impaired spatial working memory in the Y-maze.

Next, we investigated the activity of mice in the y-maze in the baseline vs vehicle conditions. As in the open field experiment, we observed changes in exploratory behavior characterized by a reduction of exploration during the vehicle condition as demonstrated by changes in the speed of movement, total distance run, immobility and by the decreased number of $y$-maze arm entries $\left(\mathrm{m} / \mathrm{s}, \quad 0.052 \pm 0.005\right.$ vs $0.028 \pm 0.003 ; t_{(4)}=$ $3.48, p<0.05$, distance $(m), 31.01 \pm 2.8$ vs $17.23 \pm 1.82 ; \mathrm{t}_{(4)}=3.4, p<0.05$, immobility $\%$, $40.36 \pm 6.16$ vs $64.9 \pm 4.8 ; t_{(4)}=-3.102, p<0.05$; entries $25 \pm 3.4$ vs $14 \pm 2.1, z=-1.06, p>0.05$ ), see Fig 3. When we analyzed the baseline vs the MK801 condition, we observed changes in speed of movement, total distance, no changes in the immobility time but an increase in the total number of $y$-maze arm entries $\left(\mathrm{m} / \mathrm{s}, 0.037 \pm 0.005\right.$ vs $0.07 \pm 0.01 ; \mathrm{t}_{(6)}=$ $-3.484, p<0.05$, distance $(m), 23.49 \pm 8.5$ vs $38.02 \pm 4.9 ; \mathrm{t}_{(6)}=-3.29, \mathrm{p}<0.05$, immobility $\%$, $57.22 \pm 6.3$ vs $38.9 \pm 7.3 ; t_{(6)}=-2.378, p>0.05$; entries $17 \pm 5.7$ vs $39.2 \pm 6.3, z=2.366$, $\mathrm{p}<0.05)$.

To measure working memory, we evaluated the animals' tendency to alternate between different arms of the $y$-maze. The final score was calculated as the percentage of correct triads performed, see methods and figure 3 . We observed no significant change in performance in the baseline vs. the vehicle condition (\% of alternation, $59.08 \pm 7.9$ vs $57.34 \pm 9.2 ; t_{(4)}=0.125, p>0.05$.). On the other hand NMDAr blockade, clearly reduced performance in the $y$-maze ( $\%$ of alternation, $62.58 \pm 4.8$ vs. $37.38 \pm 2.56 ; t_{(6)}=4, p<0.001$ ), see Fig 3F. 


\section{Y Maze}

A

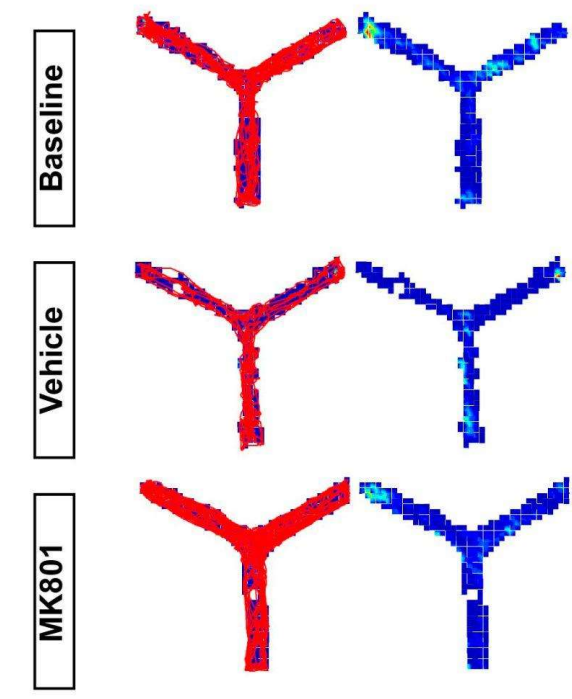

$\mathbf{F}$

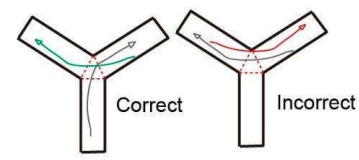

B

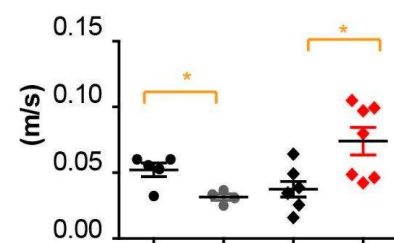

D

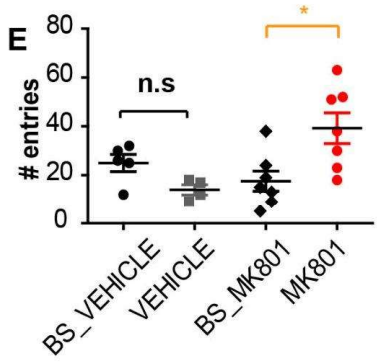

I

H BS_V Vs BS_MK

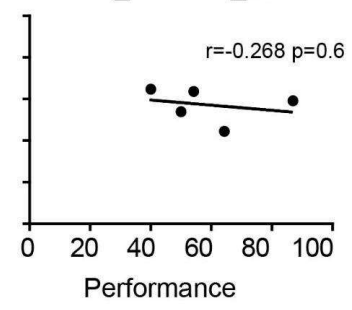

BS_V Vs Vehicle

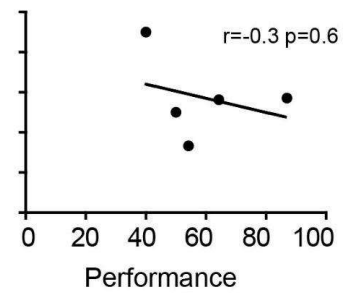

C Total Distance Run

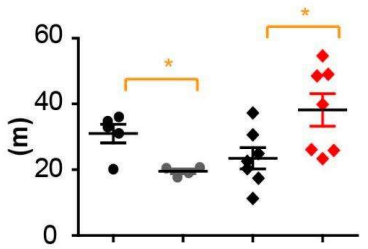

E Total Inmovility

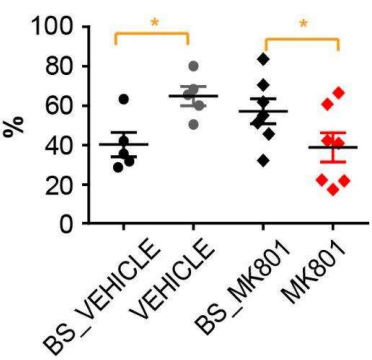

J BS_MK Vs MK

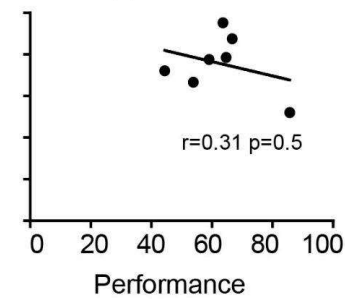

Figure 3. MK801 impaired spatial working memory. A. Representative tracking and dwelling time maps in the $y$-maze for the baseline, vehicle, and MK801 recordings. B. Mean speed was reduced during the vehicle condition and increased after MK801 administration. This trend was similar for the total distance run and the immobility times C and D. E. MK801 augmented the number of visits to the different arms. F. Examples of correct and incorrect alternations. G. Lower performance in the y-maze revealed a deficit in spatial working memory after NMDAr blockade. $\mathrm{H}, \mathrm{I}$ and J. Group performance was maintained for the y-maze across different days, but the individual behavior did not correlate between trials of the same condition, e.g., baseline. No significant correlations were found between the baselines and the experimental conditions 


\section{Effect of MK801 on CA1 oscillations during spontaneous exploration}

NMDAr blockade is thought to generate GABAergic interneuron dysfunction and changes in oscillatory activity (Jackson et al., 2004; Lee et al., 2017). Oscillatory activity is modulated by the behavioral state, especially the subject's locomotor behavior (Long et al., 2014). Here, we investigated how MK801 affected hippocampal and PFC oscillations, as well as the dialogue between these areas. We first studied the relationship between the speed of movement and CA1 theta/gamma oscillations. To carry out this analysis, we segmented the signal in non-overlapping windows of $1 \mathrm{~s}$ of duration and calculated the power spectrum and movement speed, comparing them across the different conditions.

In the relationship between oscillatory activity and speed of movement, between the baseline and vehicle conditions, see Fig 4A, we found no significant differences for theta and low gamma. However, the high gamma-speed correlation was significantly higher in the vehicle condition than in the baseline (theta/speed, $r=0.23 \pm 0.07$ vs $r=0.23 \pm 0.07$, $\mathrm{t}_{(8)}=0.041, \mathrm{p}>0.05$, low gamma/speed, $0.11 \pm 0.05$ vs $0.21 \pm 0.06, \mathrm{t}_{(8)}=-2.170, \mathrm{p}>0.05$ high gamma/speed, $0.55 \pm 0.03$ vs $\left.0.62 \pm 0.03, \mathrm{t}_{(8)}=-3.46, \mathrm{p}<0.05\right)$.

When we compared the baseline vs MK801 condition, we found that the correlation between theta, low gamma and high gamma, was significantly lower after MK801 administration (theta/speed, $\quad \mathrm{r}=0.21 \pm 0.06$ vs $\mathrm{r}=0.03 \pm 0.06, \mathrm{t}_{(8)}=2.56, \quad \mathrm{p}<0.05$, low gamma/speed, $0.11 \pm 0.06$ vs $-0.11 \pm 0.04, \mathrm{t}_{(8)}=6.82, \mathrm{p}>0.001$ high gamma/speed, $0.57 \pm 0.03$ vs $0.39 \pm 0.05, z=-2.429, p<0.01)$.

Finally, we compared the vehicle vs MK801 condition, and found significant differences in their correlations; speed vs theta, low and high gamma (theta/speed, $\mathrm{t}_{(8)}=2.41, \mathrm{p}<0.05$, low gamma/speed, $\mathrm{t}_{(8)}=7.32, \mathrm{p}<0.001$ high gamma/speed, $\left.\mathrm{z}=-2.666, \mathrm{p}<0.01\right)$. All of these differences were preserved after Bonferroni correction, except for that of the theta band.

Thus, NMDAr blocking by MK801 altered the relationship between CA1 oscillatory activity and speed of movement.

\section{Effect of MK801 on CA1 and PFC oscillatory activity.}

To control for behavioral states as a potential confounding variable influencing oscillatory activity, we calculated the power spectrum for the entire recording session over different time windows (see Fig 1 for representative recordings and Fig 4 for results). Then, we selected epochs of behavior in which the speed of movement was above $5 \mathrm{~cm} / \mathrm{s}$ during 
at least $>2 \mathrm{sec}$. We observed an almost identical oscillatory profile in CA1 and PFC when comparing baseline versus vehicle. We detected a small but significant increase in beta power during the vehicle condition for the CA1 region (beta $16-29 \mathrm{~Hz}$ (mean \pm se, $m V^{2}, 0.00067 \pm 0.0001$ vs $\left.0.00077 \pm 0.0001 t_{(8)}=-2.56, p>0.05\right)$. We found no significant difference in theta frequency across recordings (mean $\pm s e, H z, 8.10 \pm 0.2$ vs $8.13 \pm 0.2, z=-$ $0.333, p>0.05)$.

For baseline vs MK801 comparisons, we analyzed the LFP recorded in CA1 and found a significant shift towards higher theta frequencies in the MK801 condition (8.1 \pm 0.2 vs $\left.8.8 \pm 0, t_{(8)}=-8.315 p<0.001\right)$ with no changes in theta power, see Fig 4. When we looked at other CA1 oscillatory bands, we found a significant decrease in the power of alpha 12$16 \mathrm{~Hz}$ and beta $17-29 \mathrm{~Hz}$, and a significant increase in the high band of gamma, 65-130 $\mathrm{Hz}$. The PFC showed a different activity profile characterized by an increase in the power of theta but no changes in theta frequency $\left(6.9 \pm 0.5\right.$ vs $\left.7.9 \pm 0.3 t_{(8)}=-0.79 p>0.05\right)$. We found a reduction in the alpha and beta bands and an increase in the high gamma band $65-130 \mathrm{~Hz}$ as well as a striking increase in HFO power $(155-185 \mathrm{~Hz})$. Part of the recorded signal in the PFC might be volume propagated, so we performed the same analysis after referencing the PFC signal to electrodes located in different tetrodes, implanted in the PFC. This type of bipolar derivation is used to eliminate volume conductance from other brain areas. The increase in theta, high gamma, and HFO were preserved after this bipolar derivation, see Fig 4.

We completed this analysis in the CA1 LFP, looking at the power spectrum during epochs in which movement speed was below $5 \mathrm{~cm} / \mathrm{s}$. This allowed us to test for possible power spectral changes during non-exploratory behavior. In CA1, we found no significant changes in the power of theta - neither in the baseline vs vehicle nor baseline vs MK801 $\left(m V^{2}, \quad 0.0035 \pm 0.0 .0006\right.$ vs $0.0036 \pm 0.0 .0006 \mathrm{t}_{(8)}=0.607 \mathrm{p}>0.05 ; 0.0043 \pm 0.0 .0003$ vs $\left.0.0003 \pm 0.0 .0008 t_{(8)}=-1.022 p>0.05\right)$. When we looked at the low and high gamma band, we observed that these were significantly increased in the MK801 condition $\left(m V^{2}\right.$, low gamma, $0.0014 \pm 0.0 .0007$ vs $0.0019 \pm 0.0 .0003, \quad z=2.547 \mathrm{p}<0.05 ;$ high gamma, $0.00061 \pm 0.0 .0001$ vs $0.0011 \pm 0.0 .0002, z=2.666, p<0.05)$.

Finally, we calculated the ratio of change in the different bands between the baseline/vehicle vs baseline/MK801. First, we selected those bands in which scores were apparently different in the sample distribution. Significant changes in the CA1 were found between $3-9 \mathrm{~Hz}, 13-20 \mathrm{~Hz}$ and between $30-130130 \mathrm{~Hz}$ (mean $\pm s e$, au, $1.04 \pm 0.03$ vs $0.79 \pm 0.07 \mathrm{t}_{(8)}=3.0589 \mathrm{p}<0.05,1.15 \pm 0.07$ vs $0.77 \pm 0.03 \mathrm{z}=-2.666 p<0.01 ; 1.7 \pm 0.06$ vs $1.4 \pm 0.08 z=-2.31 p<0.05)$. These results indicated that delta, theta, alpha, and beta 
bands were lower in the MK801 ratio, but higher in the gamma band. In the monopolar configuration of the PFC, the comparison between the ratios baseline/vehicle and baseline/MK801 indicated that frequency bands between 0.9 to $16 \mathrm{~Hz}$, including delta, theta and alpha, and HFO were significantly increased in the MK801 condition (au, $0.99 \pm 0.03$ vs $1.5 \pm 0.1 t_{(8)}=-4.188, p<0.01,1.25 \pm 0.2$ vs $\left.2.87 \pm 0.5\right)$. We then looked for the ratio of change in the PFC after bipolar derivation. As with the single wire configuration, the bipolar derivation detected significant changes between $0.9-16 \mathrm{~Hz}, 65-100 \mathrm{~Hz}$ and in the HFO band (mean \pm se, au, $0.99 \pm 0.05$ vs $1.5 \pm 0.1 \mathrm{t}_{(8)}=-2.737, \mathrm{p}<0.05,1.25 \pm 0.2$ vs $2.87 \pm 0.5, \mathrm{t}_{(8)}=-3.212, \mathrm{p}<0.05 ; 0.9 \pm 0.02$ vs $\left.1.8 \pm 0.3, \mathrm{t}_{(8)}=-2.612, \mathrm{p}<0.05\right)$.

Thus, NMDAr blocking by MK801 affected oscillatory bands in the hippocampus and the prefrontal cortex differently. 
CA1 Recordings During Exloration on the Open field

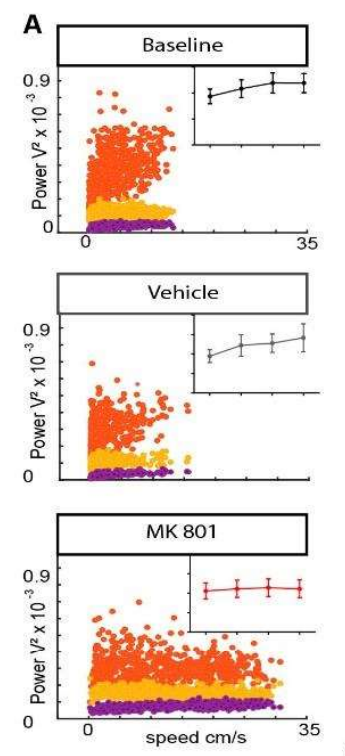
CA1
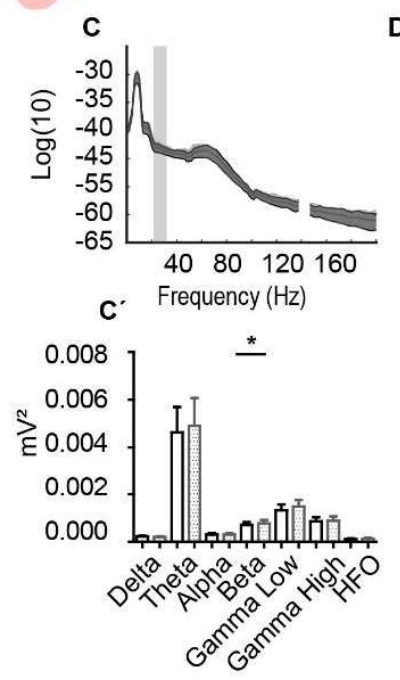

D
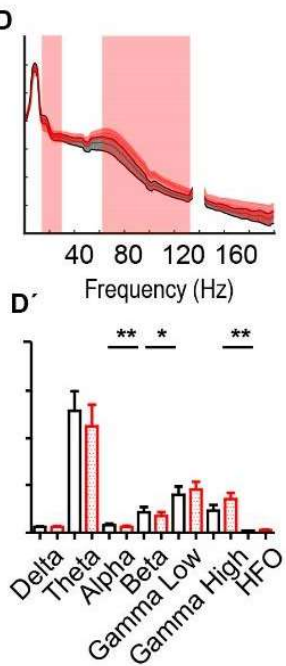

PFC

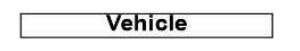

$\mathbf{F}$
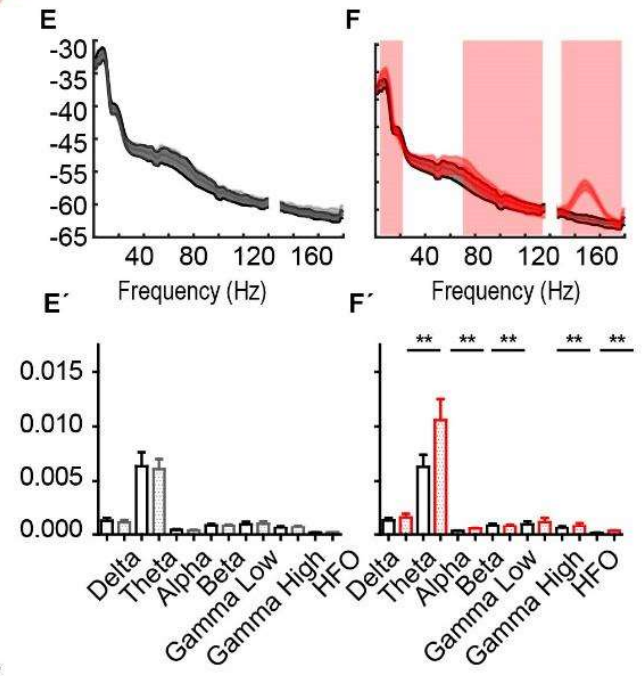

Bipolar Derivation

$\mathrm{H}$
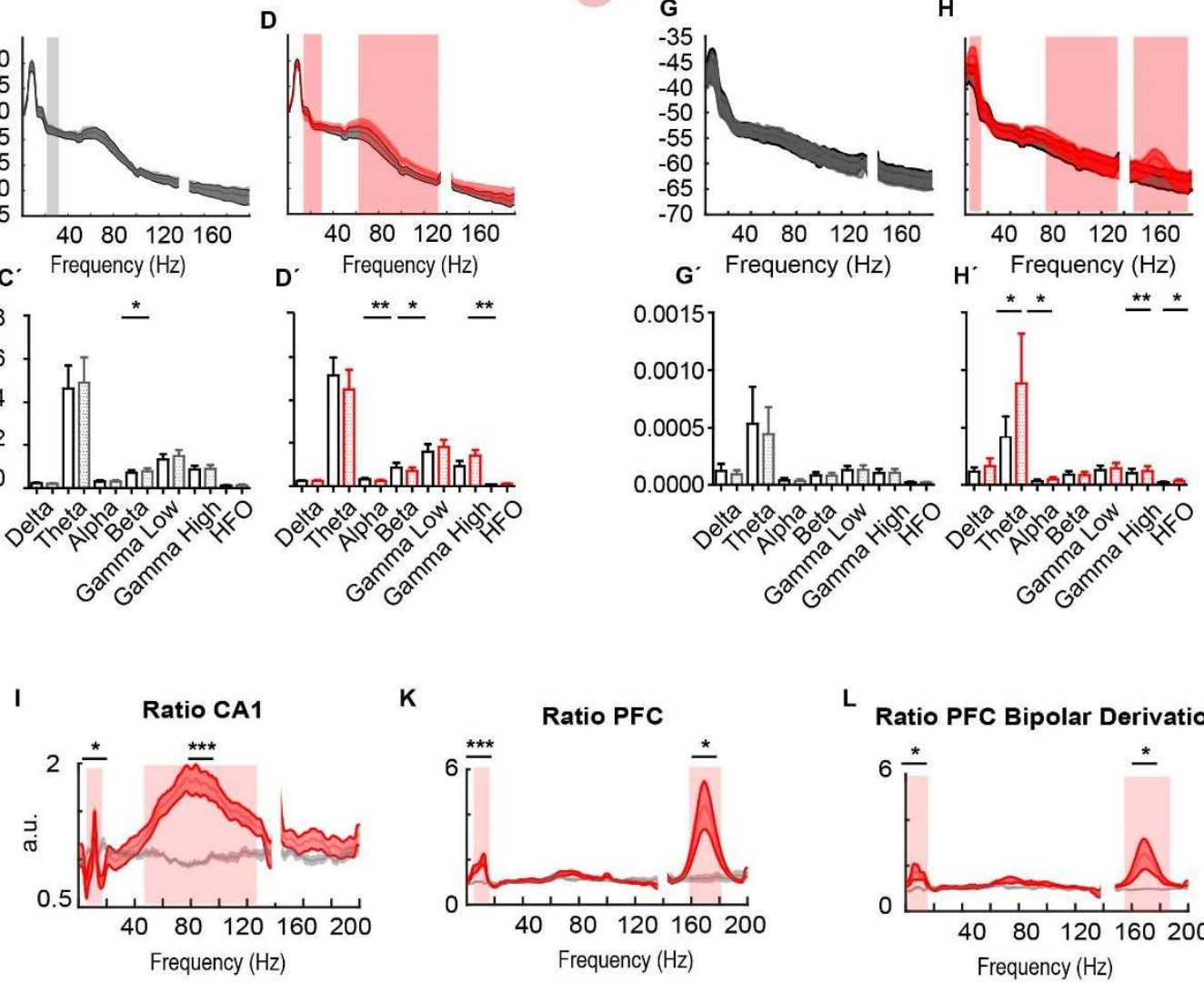

K

Ratio PFC

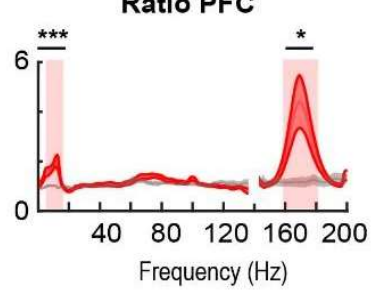

L Ratio PFC Bipolar Derivatior

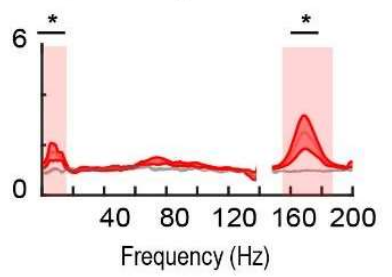

Recorded Areas

- $\mathrm{CA} 1$ PFC

Figure 4. MK801 administration disrupted oscillatory activity in the CA1 and the PFC. A. Representative scatters plots for one animal. Speed vs theta, low and high gamma. B. Speed vs oscillatory activity. MK801 widely disrupted theta and gamma relation with the speed of movement. C. Baseline vs vehicle CA1: No significant difference was found between baseline vs vehicle condition in CA1 except for the beta band, which power was higher during the vehicle 
condition. Data expressed in $\mathrm{mV}^{2}$, mean \pm se, baseline vs vehicle: Delta $(0.9-3.9 \mathrm{~Hz})$, $0.00020 \pm 0.000020$ vs $0.00019 \pm 0.000020, t(8)=1.93 p>0.05$; Theta $(4-12 \mathrm{~Hz}), 0.0046 \pm 0.001$ vs $0.0049 \pm 0.0003, \mathrm{t}(8)=-2.181, p>0.05$; alpha $(12.1-16 \mathrm{~Hz}), 0.00030 \pm 0.000$ vs $0.00031 \pm 0.000$, $\mathrm{t}_{(8)}=-0.2001, p>0.05$; beta $(16.1-29 \mathrm{~Hz}), 0.00067 \pm 0.0001$ vs $0.00074 \pm 0.0001, \mathrm{t}(8)=-2.561$, $p<0.05$; low gamma $(30-65 \mathrm{~Hz}) 0.0018 \pm 0.0002$ vs $0.0009 \pm 0.0002 z=1.59, p>0.05$; High gamma $(66-135 \mathrm{~Hz}) 0.000921 \pm 0.0002$ vs $0.00140 \pm 0.0002, z=2.666, p>0.01$; HFO $(155-185 \mathrm{~Hz})$, $0.00008 \pm 0.00001$ vs $0.0001 \pm 0.00002, z=1.125, p>0.05$. D. Baseline vs MK801 CA1. Significant differences were found for alpha, beta and high gamma in the hippocampus CA1. Delta $(0.9-3.9 \mathrm{~Hz}), 0.00024 \pm 0.00003$ vs $0.00023 \pm 0.00003, \mathrm{t}(8)=0.636 \mathrm{p}>0.05$; Theta $(4-12 \mathrm{~Hz})$, $0.0051 \pm 0.001$ vs $0.0045 \pm 0.001, \mathrm{t}(8)=1.254, \mathrm{p}<0.05$; alpha $(12.1-16 \mathrm{~Hz}), 0.00032 \pm 0.0001 \mathrm{vs}$ $0.00025 \pm 0.0001, \mathrm{t}(8)=3.477, \mathrm{p}>0.05$; beta $(16.1-29 \mathrm{~Hz}), 0,00085 \pm 0,0002$ vs $0,0007 \pm 0.0001, z=-$ 2.192, $p<0.05$; low gamma $(30-65 \mathrm{~Hz}) 0,0015 \pm 0.0003$ vs $0.0018 \pm 0.0003, z=1.955, p>0.05$; High gamma $(66-135 \mathrm{~Hz}) 0,00010 \pm 0.000027$ vs $0.00012 \pm 0.00004, z=0.89, p>0.05 ; z=-0178$, $p>0.05$; HFO $(155-185 \mathrm{~Hz}), 0,00009 \pm 0,00001$ vs $0.00011 \pm 0.00002, z=1.12 p>0.05$. E. No significant difference were found between baseline vs vehicle condition in oscillatory activity in PFC. mean \pm se, baseline vs vehicle, Delta $(0.9-3.9 \mathrm{~Hz}), 0.00026 \pm 0.00005$ vs $0.00024 \pm 0.00004, z=-0.178 p>0.05$; Theta $(4-12 \mathrm{~Hz}), 0.0012 \pm 0.0002$ vs $0.0012 \pm 0.0001$, $\mathrm{t}(8)=0.547, p>0.05$; alpha $(12.1-16 \mathrm{~Hz}), 0.000081 \pm 0.00001$ vs $0.000075 \pm 0.00001, \mathrm{t}(8)=0.96$, $\mathrm{p}>0.05$; beta $(16.1-29 \mathrm{~Hz}), 0.00018 \pm 0.00002$ vs $0.00017 \pm 0.00002, \mathrm{t}(8)=1.942, p<0.05$; low gamma $(30-65 \mathrm{~Hz}) 0.00021 \pm 0.00004$ vs $0.00022 \pm 0.00014, z=1.48, p>0.05$; High gamma (66$135 \mathrm{~Hz}) 0.00013 \pm 0.00003$ vs $0.00015 \pm 0.00003, z=1.836, p>0.05$; HFO $(155-185 \mathrm{~Hz})$, $0.000032 \pm 0.000005$ vs $0,000044 \pm 0,00001, z=0.77, p>0.05$. F. Baseline vs MK801 PFC. Significant differences were found in theta, alpha, beta, high gamma and HFO. Delta (0.9$3.9 \mathrm{~Hz}), 0.00027 \pm 0,00004$ vs $0.00032 \pm 0.00006, \mathrm{t}_{(8)}=-1.662, p>0.05$; Theta $(4-12 \mathrm{~Hz})$, $0.0012 \pm 0.0002$ vs $0.0021 \pm 0.0021, \mathrm{t}_{(8)}=-3.931, \mathrm{p}<0.01$; alpha $(12.1-16 \mathrm{~Hz}), 0.00007 \pm 0.00001$ vs $0.00011 \pm 0.00002, \mathrm{t}_{(8)}=-3.197, \mathrm{p}<0.05$; beta $(16.1-29 \mathrm{~Hz}), 0.00018 \pm 0.00003$ vs $0.00016 \pm$ $0.00002, \mathrm{t}_{(8)}=4,02, \mathrm{p}<0.01$; low gamma $(30-65 \mathrm{~Hz}) 0.00020 \pm 00.00005$ vs $0.00024 \pm 0.00008$, $z=1.95$, $p>0.05$; High gamma $(66-135 \mathrm{~Hz}) 0.00013 \pm 0.00003$ vs $0.00016 \pm 0.00005, z=2.19$, $p<0.05$; HFO $(155-185 \mathrm{~Hz}) 0.000026 \pm 0.000004$ vs $0.00006 \pm 0.00001, z=2.310, p<0.05$. G. PFC bipolar derivation Baseline vs vehicle PFC. Significant differences were found in theta, alpha, beta, high gamma and HFO. Delta $(0.9-3.9 \mathrm{~Hz}), 0.00012 \pm 0.00005$ vs $0.000090 \pm$ $0.00003, z=-1.481 p>0.05$; Theta $(4-12 \mathrm{~Hz}), 0.00053 \pm 0.0003 v s 0.00044 \pm 0.0002, z=-1.481$, $p>0.05$; alpha $(12.1-16 \mathrm{~Hz}), 0.000039 \pm 0.00001$ vs $0.000075 \pm 0.000019, \quad z=-01362 p>0.05$; beta $(16.1-29 \mathrm{~Hz}), 0.000081 \pm 0.00002$ vs $0.000077 \pm 0.00002, z=-1.244 p>0.05$; low gamma $(30-65 \mathrm{~Hz}) 0.00012 \pm 0.00003$ vs $0.00013 \pm 0,00003, z=0.652, p>0.05$; High gamma $(66-135$ $\mathrm{Hz}) 0.00010 \pm 0.00003$ vs $0.00010 \pm 0.00003, z=0.652, p>0.05$; HFO $(155-185 \mathrm{~Hz})$, $0.000021 \pm 0.000007$ vs $0.000019 \pm 0.000007, z=-1.125, p>0.05$. H. PFC bipolar derivation

Baseline vs vehicle MK801. Similar results to single wire configuration were found after bipolar derivation. Significant differences were present in the theta, alpha, beta, high gamma and HFO bands: Delta $(0.9-3.9 \mathrm{~Hz}), 0.00011 \pm 0.00003$ vs $0.00016 \pm 0.00006, z=1.955 p>0.05$; Theta $(4-12 \mathrm{~Hz}), 0.00041 \pm 0.0002 v s 0.00088 \pm 0.0004, z=2.49, p<0.05$; alpha $(12.1-16 \mathrm{~Hz})$, $0.000032 \pm 0.00001$ vs $0.000047 \pm 0.000019, z=2.49, p<0.05$; beta $(16.1-29 \mathrm{~Hz}), 0.000088 \pm$ 0.00003 vs $0.00084 \pm 0,00002, z=-1.244 p>0.05$; low gamma $(30-65 \mathrm{~Hz}) 0.00012 \pm 0.00004$ vs $0.00014 \pm 0.00003, z=1.599, p>0.05$; High gamma $(66-135 \mathrm{~Hz}) 0.00010 \pm 0.00003$ vs 0.00012 $\pm 0.000004, \quad z=2.666, \quad p<0.05$; HFO $(155-185 \mathrm{~Hz}), \quad 0.000020 \pm 0.000008 \quad$ vs $0.000032 \pm 0.000001, z=2.192, p<0.05$. 
Effects of MK801 on theta-gamma and theta-HFO interactions in the CA1 and PFC

In the hippocampus, theta-gamma modulation proceeds in an organized manner, with an increase in low gamma power, 30-60 Hz, after the peak of theta (Buzsáki et al., 2003; Valero \& de la Prida, 2018). Based on previous work (Korotkova et al., 2010), we calculated a theta/gamma modulation index (GMI). We obtained this index for the analysis of LFPs recorded in the hippocampus and PFC. We calculated the GMI for low gamma $30-65 \mathrm{~Hz}$, high gamma, $66-130 \mathrm{~Hz}$, and for theta-HFO co-modulation in the PFC. Similar to previous work, we performed this analysis in the single-ended configuration (Tamura et al., 2017).

The theta/gamma index calculated for the low gamma band significantly increased in the vehicle condition vs the baseline (baseline vs vehicle, $0.23 \pm 0.03$ vs $0.28 \pm 0.03, \mathrm{t}_{(8)}=2.75$, $\mathrm{p}<0.05)$. On the other hand, MK801 significantly reduced theta/gamma co-modulation (baseline vs $M K 801,0.21 \pm 0.01$ vs $0.14 \pm 0.01, t_{(8)}=5.6, p<0.001$ ). No significant changes were observed for the high gamma band between baseline vs vehicle or baseline vs MK801 (baseline vs vehicle, $0.22 \pm 0.03$ vs $0.23 \pm 0.04$; baseline vs MK801, $0.21 \pm 0.03$ vs $\left.0.19 \pm 0.02 ; \mathrm{t}_{(8)}=-0.33, \mathrm{p}>0.05 ; \mathrm{t}_{(8)}=1.4, \mathrm{p}>0.05\right)$

The analysis of the theta/gamma modulation in the PFC followed a similar profile to that of CA1. Thus, GMI was higher for the low gamma in the vehicle condition vs the baseline and was significantly reduced after NMDAr blockade (baseline vs vehicle, $0.13 \pm 0.001$ vs $0.18 \pm 0.004, \mathrm{t}_{(8)}=-2.4, \mathrm{p}<0.05$, baseline vs MK801, $0.12 \pm 0.004$ vs $0.05 \pm 0.009, ; \mathrm{t}_{(8)}=7.06$, $\mathrm{p}<0.001)$. In the high gamma band, we found higher $\mathrm{GMI}$ in the vehicle condition vs baseline, which was lowered after MK801 administration (baseline vs vehicle, $0.11 \pm 0.01$ vs $0.15 \pm 0.01, \mathrm{t}_{(8)}=-3.65, \mathrm{p}>0.001$; baseline vs MK801 $0.09 \pm 0.01$ vs $0.005 \pm 0.002,, \mathrm{t}_{(8)}=$ 9.04, $\mathrm{p}>0.001)$. We found that HFO was strongly influenced by the ongoing theta recorded in the PFC, (baseline vs vehicle, $0.11 \pm 0.01$ vs $0.12 \pm 0.01 \mathrm{t}_{(8)}=-0.52, p>0.05$; baseline vs MK801, $0.09 \pm 0.01$ vs $\left.0.26 \pm 0.003, \mathrm{t}_{(8)}=-4.9, \mathrm{p}<0.001\right)$, see Fig 5 .

These data suggest that NMDAr blocking by MK801 impaired theta-gamma comodulation in the hippocampus, as well as theta-HFO co-modulation in the PFC during spontaneous exploration. 


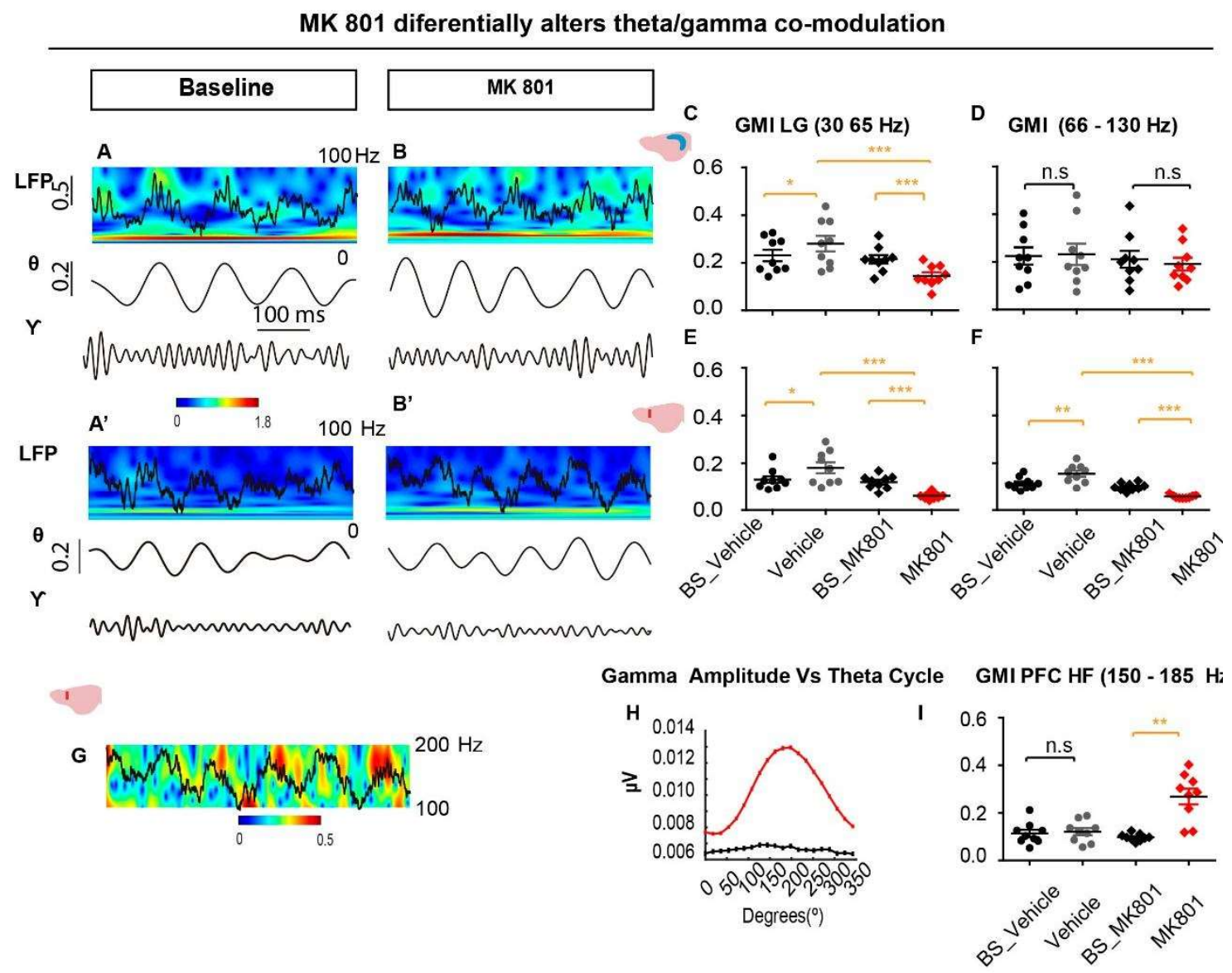

Figure 5. MK801 administration disrupted theta/gamma co-modulation. $A$, B. Local field potential, wavelet, and filtered signal for theta and gamma in CA1 and PFC in the baseline and after MK801 administration. C, D. Theta/gamma co-modulation was significantly altered for low gamma after MK801 administration. Also, GMI was higher during the vehicle condition for the low gamma. E, F. Similar results were found in PFC. G. Raw LFP recorded in PFC, wavelet revealed the strong modulation of HFO after NMDAr blockade. H. HFO are strongly modulated by theta activity in the PFC. This modulation is significantly higher than in the baseline condition.

Effects of MK801 on hippocampal-PFC interaction during spontaneous exploration.

As a measure of brain area coordination, we investigated the coherence for each frequency band in a single-ended electrode configuration. We observed no significant changes in the baseline vs the vehicle condition. However, we found a marginal but significant increase in the delta band coherence after MK801 administration, $(0.60 \pm 0.005$ vs $\left.0.63 \pm 0.01, \mathrm{t}_{(8)}=-2.54, \mathrm{p}<0.05\right)$. To control for possible signal volume propagated from other regions, we calculated the same coherence values after applying a bipolar 
derivation. In this case, we observed a minimal but significant increase in the low gamma band $30-65 \mathrm{~Hz}$ for the vehicle condition $(0.54 \pm 0.002$ vs $0.543 \pm 0.001, z=-2.07, p<0.05)$. In the MK801 condition, the delta coherence augmentation was preserved but the alpha band significantly increased (delta and alpha, $0.60 \pm 0.009$ vs $0.62 \pm 0.01, \mathrm{t}_{(8)}=-3.64$, $\mathrm{p}<0.001 ; 0.55 \pm 0.006$ vs $0.57 \pm 0.005, \mathrm{t}_{(8)}=-3.01, \mathrm{p}<0.01$ ), see Fig 6 .

Long-range co-modulation of theta/gamma activity has been proven relevant for the interaction of distant brain areas during spatial working memory tasks (Tamura et al., 2017). Thus, we wanted to determine if the interaction between CA1 theta and PFC gamma was altered after NMDAr blockade. We calculated the GMI between the ongoing theta in CA1 and the gamma band recorded in the PFC, and found that theta/gamma modulation was increased in the baseline vs vehicle condition for low, high gamma and HFO (low gamma, $0.12 \pm 0.015$ vs $0.17 \pm 0.019, \mathrm{t}_{(8)}=-4.61, \mathrm{p}<0.01$; high gamma, $0.087 \pm 0.01$ vs $0.12 \pm 0.01, \mathrm{t}_{(8)}=-5.43, \mathrm{p}<0.001 ; H F O, 0.07 \pm 0.01$ vs $0.09 \pm 0.009, \mathrm{t}_{(8)}=-2.94$, $\mathrm{p}<0.01$ ). After the administration of MK801, GMI was significantly reduced for low and high gamma. However, we found no significant changes for the modulation index between CA1 theta and PFC in the HFO (low gamma, $0.13 \pm 0.008$ vs $0.06 \pm 0.004, \mathrm{t}_{(8)}=$ 4.77, $\mathrm{p}<0.01$; high gamma, $0.08 \pm 0.007$ vs $0.05 \pm 0.003, \mathrm{t}_{(8)}=-5.43, \mathrm{p}<0.001 ;$ HFO, $0.07 \pm 0.004$ vs $\left.0.08 \pm 0.01, t_{(8)}=-1.15, p>0.05\right)$, see Fig 6 . 
CA1-PFC interaction during exloration in the open field

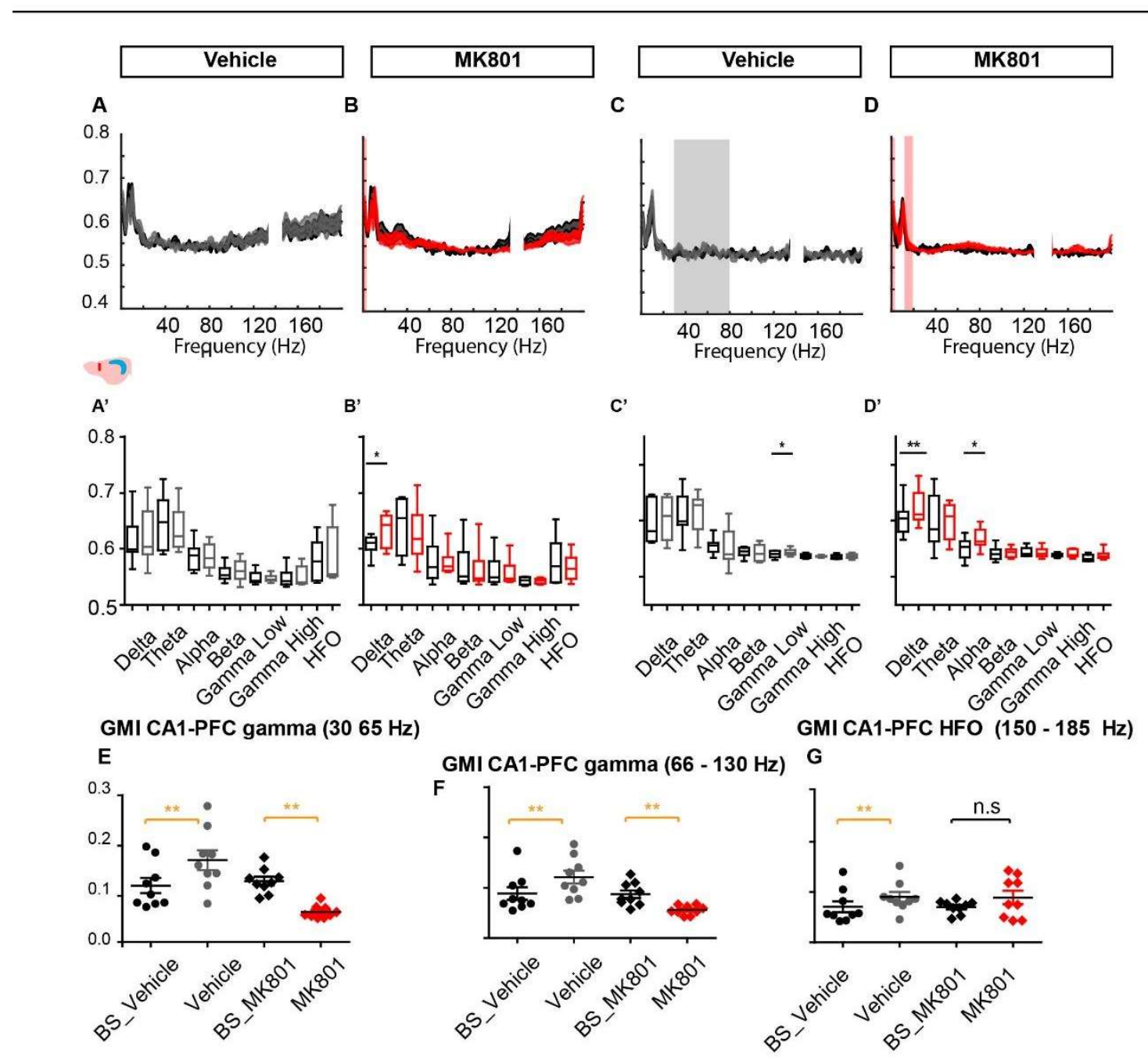

Figure 6. MK801 administration altered CA1-PFC interaction. A,B. Coherence values for the baseline vs vehicle and baseline vs MK081 obtained in single electrode configuration. $A^{\prime}, B^{\prime}$ coherence distribution for different bands. E,F,G CA1-PFC theta/gamma co-modulation and theta/HFO co-modulation. Modulation index revealed higher values for the vehicle condition vs the baseline. On the contrary, MK801 diminished theta/gamma co-modulation. HFO in the OFC were not altered after MK801 vs the baseline 
Theta/gamma modulation is enhanced during correct alternations in the y-maze.

We classified correct vs incorrect alternations and then analyzed the power spectrum, coherence, and theta/gamma modulation in the CA1 and PFC. Controlling for the locomotor activity accompanying correct and incorrect alternations, we found no difference in the speed of movement within the baseline and MK801 conditions between correct and incorrect trials (baseline, correct vs incorrect, speed: $0.12 \pm 0.007$ vs $0.10 \pm 0.009, \mathrm{t}_{(8)}=1.31, \mathrm{p}>0.05 ; M K 801: 0.18 \pm 0.01$ vs $\left.0.17 \pm 0.013, \mathrm{t}_{(6)}=1.9, \mathrm{p}<0.05\right)$, see Fig 7.

First, we looked at the CA1 power spectrum in the baseline condition to establish the oscillatory profile of successful retrieval. We found that theta power was numerically higher in the correct vs incorrect alterations, however this change did not reach statistical significance. We found no significant differences for the low and high gamma bands $\left(m V^{2}\right.$, baseline, correct vs incorrect, theta: $0.0055 \pm 0.001$ vs $0.0048 \pm 0.001, z=-1.352$, p>0.05; low gamma: $0.0016 \pm 0.0004$ vs $0.0015 \pm 0.0004, z=-0.169, p>0.05$; high gamma: $0.0011 \pm 0.0004$ vs $0.0011 \pm 0.0004, z=-0.169, p>0.05)$. To determine if CA1 theta/gamma modulation was relevant for memory performance, we obtained the GMI for low and high gamma in the CA1 region. We found significant differences in the thetalow gamma but not in the theta-high gamma modulation for the correct vs incorrect trials (baseline, correct vs incorrect, theta/low gamma, $0.47 \pm 0.03$ vs $0.31 \pm 0.01, \mathrm{t}_{(6)}=4.93$, $\mathrm{p}>0.01$; theta/high gamma, $0.34 \pm 0.03$ vs $\left.0.291 \pm 0.03, \mathrm{t}_{(6)}=1.8, \mathrm{p}>0.05\right)$.

Second, we looked at the PFC power spectrum in the baseline condition to establish the oscillatory profile of successful retrieval. We observed no significant difference in the power of theta, low gamma or high gamma (baseline, correct vs incorrect, theta power, $0.0011 \pm 0.0002$ vs $0.0012 \pm 0.0002, \mathrm{t}_{(6)}=-1.4, \mathrm{p}>0.05$; low gamma power, $0.00020 \pm 0.000$ vs $0.00019 \pm 0.000, z=-0.8451, p>0.05$, high gamma, $0.00016 \pm 0.0000$ vs $0.00016 \pm$ $0.0000, z=-2.194, p<0.05)$. We further investigated if theta/gamma modulation presented a different pattern in the correct vs incorrect alternations. We found that theta/gamma, low and high, co-modulation was stronger during successful memory retrieval (mean \pm se, au, baseline, correct vs incorrect, theta/low gamma, $0.23 \pm 0.03$ vs $0.17 \pm 0.03, z=-2.36$, $\mathrm{p}>0.05$; theta/high gamma, $0.18 \pm 0.01$ vs $0.13 \pm 0.02, \mathrm{t}_{(6)}=11.06, \mathrm{p}>0.001$ ).

Looking at the communication between the hippocampus and the PFC, we did not find significant differences in the coherence for theta, or for low and high gamma oscillations between correct and incorrect alternations (au, baseline, correct vs incorrect, theta, $4.34 \pm 0.18$ vs $4.3 \pm 0.22, \mathrm{t}_{(6)}=0.36, \mathrm{p}<0.05$; low gamma, $15.6 \pm 0.53$ vs $14.38 \pm 0.24 \mathrm{t}_{(6)}=$ 2.13, $p<0.05$; high gamma, $27.13 \pm 0.8$ vs $\left.28.35 \pm 0.84 \mathrm{t}_{(6)}=-1.37, p<0.05\right)$. However, we 
found that both, theta/low and theta/high long range gamma co-modulation were significantly higher during correct alternations (baseline, correct vs incorrect, theta/low gamma, $0.37 \pm 0.02$ vs $0.25 \pm 0.03, \mathrm{t}_{(6)}=6.34, \mathrm{p}>0.01$; theta/high gamma, $0.25 \pm 0.01$ vs $\left.0.16 \pm 0.01, t_{(6)}=5.09, p>0.01\right)$.

After characterizing the oscillatory profile during memory retrieval in the baseline condition, we sought to investigate the oscillatory activity associated with NMDAr blockade and its accompanying spatial working memory impairments. We examined CA1 oscillatory activity finding no significant differences in theta, low and high gamma during correct vs incorrect alternations $\left(m V^{2}, M K 801\right.$, correct vs incorrect, theta: $0.0049 \pm 0.001$ vs $0.0045 \pm 0.001, \mathrm{t}_{(8)}=1.404, \mathrm{p}>0.05$; low gamma: $0.0019 \pm 0.0004$ vs $0.0018 \pm 0.0004, z=-1.118, p>0.05$; high gamma: $0.0017 \pm 0.0004$ vs $0.0016 \pm 0.0004$, $\left.t_{(6)}=0.247, p<0.05\right)$. When we looked at the CA1 theta/low and high gamma modulation indexes in the correct vs incorrect alternations, we found that they were all higher in the correct vs incorrect alternations (au, MK801, correct vs incorrect, theta/low gamma, $0.35 \pm 0.02$ vs $0.23 \pm 0.01, \mathrm{t}_{(6)}=7.1, \mathrm{p}>0.001$; theta/high gamma, $0.31 \pm 0.03$ vs $0.25 \pm 0.02$, $\left.t_{(6)}=3.97, p>0.001\right)$. Next, we looked for possible changes in the PFC's oscillatory activity and observed significant difference in the theta band but not within the low and high gamma oscillations $\left(m V^{2}, M K 801\right.$, correct vs incorrect, theta: $0.0012 \pm 0.0002$ vs $0.00014 \pm 0.0002, \mathrm{t}_{(6)}=-2.844, \mathrm{p}>0.05$; low gamma: $0.00020 \pm 0.0002$ vs $0.0025 \pm 0.0001$, $z=-0.507, p>0.05$; high gamma: $0.00033 \pm 0.0001$ vs $0.00031 \pm 0.0001, t_{(6)}=0.923$, $p>0.05)$. Finally, we looked for PFC changes on the theta/gamma modulation, and found that theta/gamma modulation, low and high bands, were significantly higher in the correct vs incorrect trials (au, MK801, correct vs incorrect, theta/low gamma, $0.31 \pm 0.02$ vs $0.17 \pm$ $0.01, \mathrm{t}_{(6)}=8.55, \mathrm{p}>0.001$; theta/high gamma, $0.23 \pm 0.03$ vs $0.25 \pm 0.02, \mathrm{t}_{(6)}=3.97$, $p>0.001$ ). We found no significant differences for theta, low and high gamma coherence between CA1 and PFC (MK801, correct vs incorrect, theta, $4.34 \pm 0.18$ vs $4.30 \pm 0.22$, $\mathrm{t}_{(6)}=0.36, \mathrm{p}<0.05$; low gamma, 15.6 \pm 0.53 vs $14.38 \pm 0.24, \mathrm{t}_{(6)}=2.13, \mathrm{p}<0.01$; high gamma, $27.13 \pm 0.8$ vs $\left.28.35 \pm 2.24, \mathrm{t}_{(6)}=-1.3, \mathrm{p}<0.05\right)$. To complete our analysis, we looked for changes in the long-range theta/gamma co-modulation between CA1 PFC. We found that theta/gamma modulation was higher for the low and high gamma bands in the correct vs incorrect alternations (correct vs incorrect, theta/low gamma, $0.31 \pm 0.02$ vs $0.17 \pm 0.01, \mathrm{t}_{(6)}=8.55, \mathrm{p}<0.01$; theta/high gamma, $0.23 \pm 0.01$ vs $0.13 \pm 0.01, \mathrm{t}_{(6)}=5.33$, $\mathrm{p}<0.01)$.

Therefore, theta/gamma co-modulation index was consistently higher in the correct vs incorrect trials. For this reason, we explored if the theta/gamma co-modulation obtained for the complete $y$-maze recording session correlated with the performance of mice in 
the baseline and in the MK801 condition (see Fig 8). We observed that the CA1 theta/ low gamma co-modulation was positively correlated with the performance but in a nonsignificant manner. On the other hand, hippocampal theta/ high gamma co-modulation did not correlate with mice performance (CA1 theta/low gamma, $r=0.397, p>0.05$; theta/high gamma, $r=-0.02, p>0.05)$. Then we looked at theta/gamma co-modulation in the PFC. We found that both theta/gamma co-modulation values presented high and significant correlation with the performance of mice (PFC theta/low gamma, $r=0.83$, $\mathrm{p}<0.05$; theta/high gamma, $\mathrm{r}=0.86, \mathrm{p}<0.05)$. Long-range co-modulation between CA1 and PFC was also investigated. We observed that CA1-PFC theta/low gamma comodulation significantly correlated with the performance while the high gamma presented a positive but not significant correlation (CA1PFC theta/low gamma, $r=0.86$, $\mathrm{p}<0.05$; theta/high gamma, $r=0.593, \mathrm{p}>0.05$ ). Then we investigated the effects of NMDAr blockade in the relationship between theta/gamma co-modulation and performance. We found that all correlations disappeared or were attenuated. not reaching statistical significance (CA1 theta/low gamma, $r=-0.26, p>0.05$; theta/high gamma, $r=0.2, p>0.05$; (PFC theta/low gamma, $r=0.45, p>0.05$; theta/high gamma, $r=0.04, p>0.05 ;$ CA1PFC theta/low gamma, $r=0.537, p>0.05$; theta/high gamma, $r=0.6, p>0.05)$. These results indicate that local and long-range theta/gamma co-modulation might be relevant for memory performance in the $y$-maze and that MK801 administration disrupts the communication between the CA1 and the PFC. To investigate this further, we also explored possible relations between the power spectrum and coherence values during the complete y-maze session and the animal's performance. No significant correlation was found for any of the frequency bands, neither in power nor coherence (supplementary figure S2). 
Theta/gamma co-modulation during spatial performance
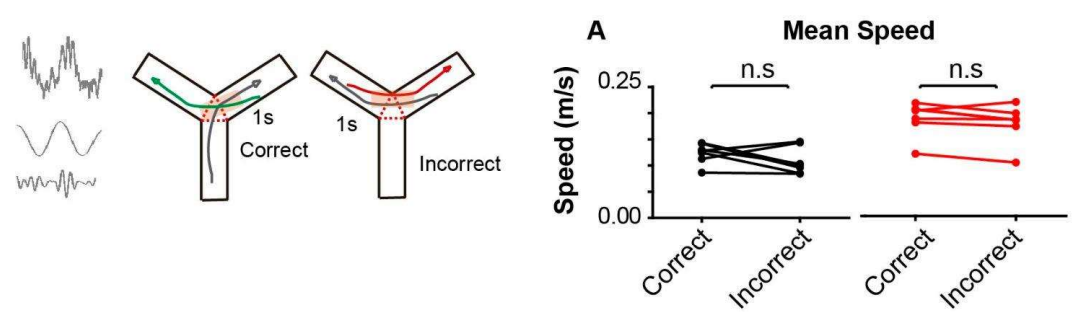

CA1

B

$$
\text { Low } Y 30 \mathrm{~Hz}-65 \mathrm{~Hz} \text { C High } \mathrm{Y} 65 \mathrm{~Hz}-130 \mathrm{~Hz}
$$

Baseline

MK801 Baseline

MK801

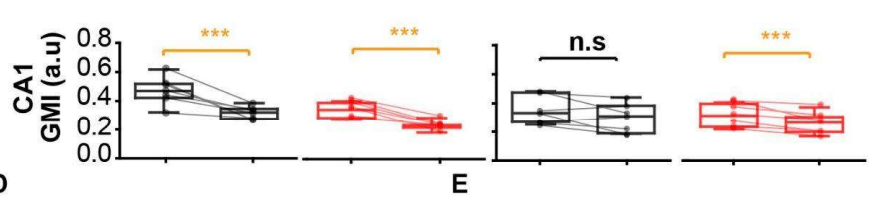

PFC

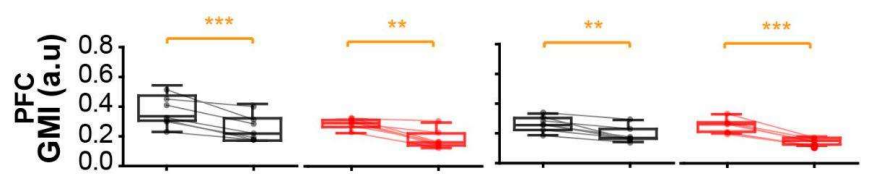

$\mathbf{F}$

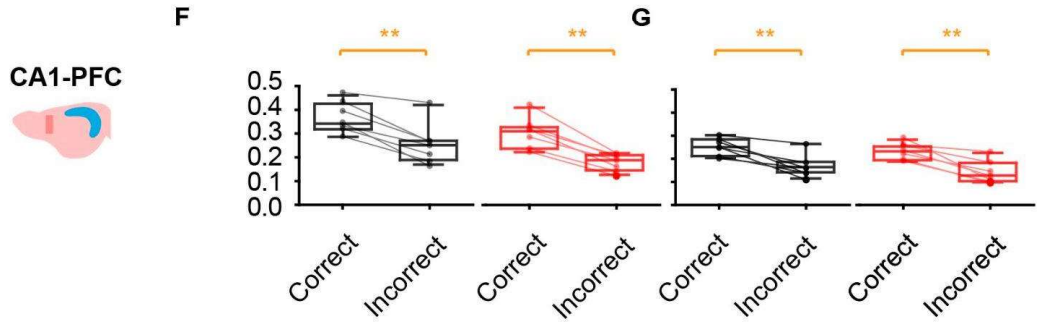

Figure 7. Theta/gamma modulation is consistently higher in the correct trials during the $y$ maze. A. No significant differences were found for the speed of movement in correct vs incorrect alternations. This indicates that changes in the LFP might not be accounted for by the speed of movement. $B, C, D, E, F, G$. Theta/gamma modulation for the different bands shows consistently higher values for the correct vs the incorrect alternations. This was similar in CA1, $\mathrm{PFC}$, and in the long-range CA1-PFC, co-modulation. 


\section{Theta/gamma co-modulation during spatial performance}

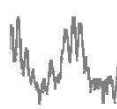

CA1
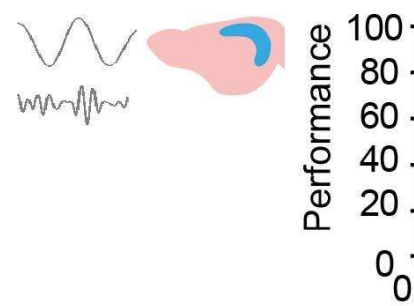

C

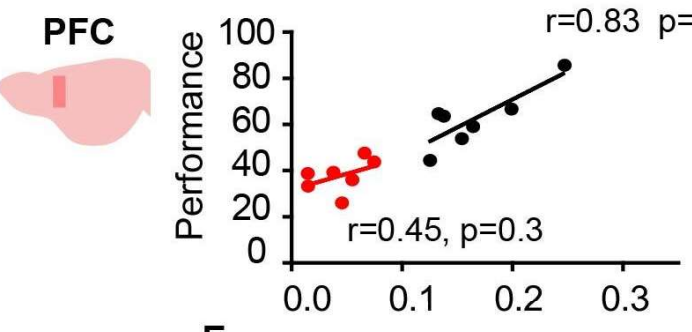

E

\section{Low $Y 30 \mathrm{~Hz}-65 \mathrm{~Hz}$}

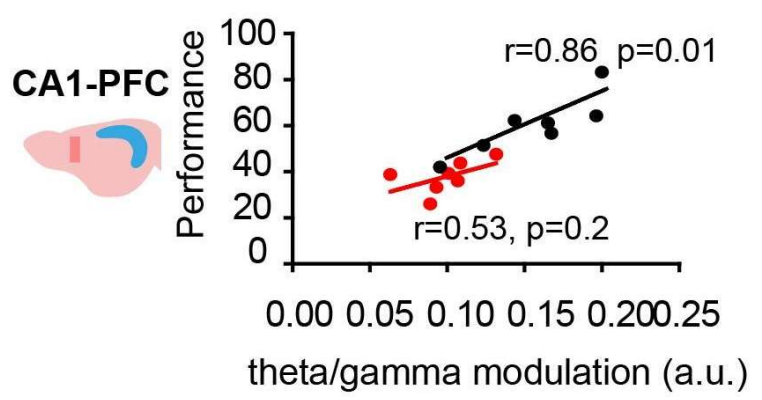

B

High Y65 Hz-130 Hz

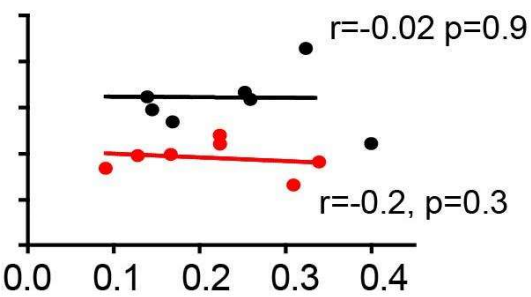

D

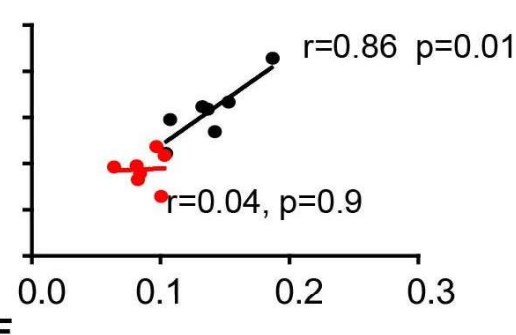

$\mathbf{F}$

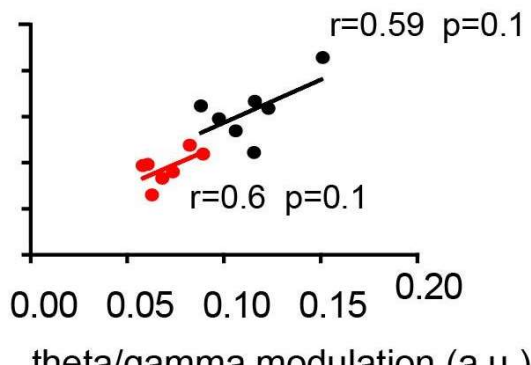

Figure 8. Theta/gamma modulation during the y maze. Theta-co-modulation correlated with the performance of mice in the baseline. This correlation was attenuated after NMDAr blockade. A., B, C, D, E, F correlation values for the theta-gamma co-modulation with the performance. 


\section{Discussion}

\section{NMDAr blockade induced positive-like symptoms and spatial working memory deficits}

Positive symptoms such as hallucinations, delusions, or hyperactivity are one of the hallmarks of schizophrenia (Owen et al., 2016). Throughout our experiments, MK801 induced hyperlocomotion in mice, increasing the speed of movement, exploratory time and the total number of entries in the y-maze. The augmentation of motor behavior was consistent in the open field and the y-maze and can be interpreted as reproducing schizophrenia's positive symptoms. This hyperactivity could be related to increased levels of dopamine release in the striatum, possibly mediated by MK801's action on NMDAr in PV+ interneurons (Belforte et al., 2010; Bygrave et al., 2016; Carlén et al., 2012).

Another of the hallmarks of schizophrenia is its associated cognitive deficits, especially those related to executive function, which are accompanied by aberrant oscillatory activity (Lewis, 2012; Uhlhaas \& Singer, 2010). In agreement with previous work (Bygrave et al., 2016), MK801 blockade impaired spatial working memory, a form of executive function, in the y-maze memory test (Callicott et al., 2000; Miedel et al., 2017).

Therefore, NMDAr hypofunction might be at the heart of different positive and cognitive symptoms observed in schizophrenia either directly or indirectly, e.g. mediating the activity of dopamine levels.

\section{NMDAr blockade altered the relationship between hippocampal oscillations and locomotion}

In physiological conditions, the power and the frequency of theta and gamma oscillations correlate with the speed and the acceleration of movement, mediating spatial cognition (Chen et al., 2011; Kropff et al., 2021; Long et al., 2014; Whishaw \& Vanderwolf, 1973). This is further supported by the fact that the association strength between theta and speed predicts the performance in spatial tasks (Richard et al., n.d.; Young et al., 2020). We observed that MK801 disturbed the normal association between movement speed and theta and gamma activity. By changing the relationship between oscillatory activity and motor behaviour, NMDAr hypofunction might cause the loss of spatial information in neurons, the impairment of the internal odometer and the integration of egocentric and 
allocentric information as well as the functional disconnection between different brain regions (Housh et al., 2014; Inostroza et al., 2013; Jackson et al., 2004; Terrazas et al., 2005).

\section{NMDAr blockade differentially altered the oscillatory activity in the hippocampus and PFC}

Previous work indicated that NMDAr blockade produced similar effects across different brain regions. However, in our experiments, MK801 produced different oscillatory profiles in the hippocampus and PFC. While oscillatory changes in the CA1 were characterized by an increase in theta frequency and gamma power, oscillatory activity under MK801 in the PFC was characterized by an increase in theta, beta, high gamma and HFO. Unlike in previous reports (Olszewski et al., 2013), changes in the PFC oscillations, including theta, gamma, HFO, etc. were maintained after bipolar derivation. Reductions of hippocampal theta have been described in previous work ((Hargreaves et al., 1997; Kiss et al., 2013; Kittelberger et al., 2012) and to our knowledge, there is no previous evidence of theta power augmentation after NMDAr blockade. The differential effect in hippocampal theta vs PFC, indicates that the increase of theta power in the PFC region is most probably not propagated but locally generated.

The emergence of HFO in the PFC following NMDAr blockade is an intriguing phenomenon, possibly produced by the alteration of the firing frequency of interneurons and pyramidal neurons (Homayoun \& Moghaddam, 2007) and the desynchronization of different clusters of neurons (Ibarz et al., 2010). On the other hand, the strong relationship between theta activity and high HFO oscillations suggests that higher frequency phenomena are dependent on lower frequency events.

Our results indicate that MK801 produced a moderate effect in the coherence between hippocampus and PFC involving Delta and Alpha frequency bands. We further observed that the theta/gamma co-modulation between the hippocampus and PFC was diminished after MK801 administration. It is relevant to highlight that HFOs recorded in the PFC were not modulated by hippocampal theta after NMDAr blockade, further supporting the idea that HFOs in the PFC are locally generated and independent from hippocampal activity. The alteration of long-range modulation and the local disruption of theta and gamma activity might be generated by shared mechanisms.

The circuits connecting the hippocampus and the PFC are complex. The PFC receives direct inputs from the intermediate and ventral hippocampus and indirect inputs from the dorsal hippocampus through the thalamic nucleus. This complexity should be taken into 
account, and future work should aim to record from the dorsal and ventral hippocampus and the PFC simultaneously (Adhikari et al., 2009; Hoover \& Vertes, 2007; Tamura et al., 2017).

\section{NMDAr blockade diminished theta/gamma.}

The co-modulation of different oscillations, especially theta/gamma, is key for the successful organization of neuronal ensemble activity and information processing in local and long-range networks (György Buzsáki \& Watson, 2012; Lopez-Pigozzi et al., 2016; Navas-Olive et al., 2020; Sigurdsson \& Duvarci, 2016). MK801 administration reduced theta/gamma co-modulation in the CA1 and PFC. This decrease affected low and high gamma bands, suggesting that theta/gamma coordination depends on NMDAr normal function and most probably on PV+ interneurons (Korotkova et al., 2010; Lopez-Pigozzi et al., 2016). The observed changes in hippocampal theta and gamma activity might be associated with modifications in neuron activity involving the firing rate, spike train organization, and network/neuron loss of coherence (Homayoun \& Moghaddam, 2007).

Previous work indicates that hippocampal theta power, the coherence between the hippocampus and the PFC, and theta/gamma co-modulation is necessary for spatial working memory (Sigurdsson et al., 2010; Tamura et al., 2017). We found no significant changes in theta and gamma coherence between CA1 and PFC during correct vs incorrect trials in the baseline and MK801 conditions. On the other hand, theta-gamma co-modulation was significantly higher in the LFP recorded in the CA1 and PFC for correct trials, in the baseline and the MK801 conditions. We observed that this increase was also present in the CA1-PFC long-range theta-gamma co-modulation, again, in both conditions. We could also observe that theta/gamma co-modulation in PFC and between CA1 and the PFC predicted animal performance in the y-maze. However, we found no significant changes in theta and gamma coherence between CA1 and the PFC during correct vs incorrect trials. Therefore, theta/gamma modulation might be necessary for spatial working memory, helping the coordination of local and long-range networks and, the reduction of theta/gamma PFC and CA1 co-modulation could reflect the disorganization of local and distal circuit interaction, altering information processing that in turn disrupts normal behavior and cognition.

\section{The effects of NMDAr hypofunction might be mediated by different factors}


Our study found that MK-801 alters the typical relationship between oscillations and motor behavior, theta/gamma co-modulation, and cognition. However, the cellular mechanisms underlying these changes are not well understood. It is likely that different cell types bear different roles in NMDAr hypofunction's pathophysiology. While the expression of NMDAr on pyramidal neurons seems necessary for MK801's alteration of the interaction between the hippocampus and PFC, NMDAr expression in interneurons appears to mediate the motor effects of MK801 (Belforte et al., 2010; Bygrave et al., 2016; Carlén et al., 2012; Hudson et al, 2020).

With respect to interneurons, previous work demonstrated that partial disconnection of $\mathrm{PV}+$ interneurons in excitatory-inhibitory circuits specifically affected gamma rhythms and executive function, generating a schizophrenia-like phenotype. On the other hand, a similar manipulation of cholecystokinin (CCK+) interneurons specifically affected theta oscillations and spatial cognition (Del Pino et al., 2017; delPino et al., 2013). Scrutinizing the role of different interneuron types by means of opto-tagging and manipulating NMDAr activity during different conditions would help unveil the micro and macro circuits involved in oscillatory activity, cognition, and the link between both(Antonoudiou et al., 2020; Royer et al., 2012).

The dynamic expression of NMDAr subtypes during neurodevelopment, across brain regions (Monyer et al., 1994; Murillo et al., 2021) and across neuronal types (Engelhardt et al., 2015) may explain how distinct neurons are responsible for schizophrenia's symptoms. Therefore, investigating the role of unconventional receptors, e.g. NMDAr containing the GluN3A subunit, might help us understand the different roles of NMDAr subunits in schizophrenia. The differential expression of these receptors in the adult brain with high levels of GluN3A subunits preserved in the PFC and the ventral hippocampus might indicate a relevant role of these subunits in the dialog between the hippocampus and PFC (Murillo et al., 2021; Otaño et al, 2016).

To conclude, we showed that NMDAr blockade by MK801 induced positive and cognitive symptoms, altering the relationship between oscillations and locomotion and impairing theta/gamma co-modulation. We also found that changes in oscillatory activity were brain area-specific. NMDAr's effect on different neuronal populations, and these neuronal population's specific roles in different brain areas, might explain the heterogeneity of the changes we observe under MK801. Therefore, further investigating how aberrant oscillatory activity, other neuronal populations, and different NMDAr subtypes contribute to schizophrenia's behavioral and cognitive deficits will be crucial to fully understand the mechanisms underlying this disorder and discover new therapies. 


\section{Author contributions}

JRBM and RR designed the experiments. JRBM and PA implemented the experiments, developed and implemented the analysis toolbox. JRBM, RR and PA discussed and interpreted the results. VB and LM supported the project providing resources for its development. JBRM wrote the paper and the manuscript was further review and data discussed by RR, PA..

\section{Acknowledgments}

We would like to thank Laia Serratosa Capdevila for her editing assistance. We thank Liset Menéndez de La Prida for her comments and suggestions in the initial version of the manuscript. Also, we want to thank the support provided by the members of Victor Borrell Lab and.

Funding: This project was supported by the Spanish State Research Agency, "Ministerio de Ciencia, Innovación y Universidades" (RTI2018-097474-A-100) and "Effect of RO compounds on the electrophysiological coupling of hippocampal-prefrontal circuits". F. Hoffmann-La Roche Ltd. by obtained by JRBM.

VB was supported by grants from the European Research Council (309633) and the Spanish State Research Agency (PGC2018-102172-B-I00, as well as through the "Severo Ochoa" Programme for Centers of Excellence in R\&D, ref. SEV-2017-0723). 


\section{References}

Housh, AA., Berkowitz, LE., Ybarra I., Kim EU., Lee BR,. (2014). Impairment of the anterior thalamic head direction cell network following administration of the NMDA antagonist MK-801. Brain Research Bulletin, 109, 77-87. https://doi.org/10.1016/J.BRAINRESBULL.2014.09.012

Abekawa, T., Ito, K., Nakagawa, S., \& Koyama, T. (2007). Prenatal exposure to an NMDA receptor antagonist, MK-801 reduces density of parvalbuminimmunoreactive GABAergic neurons in the medial prefrontal cortex and enhances phencyclidine-induced hyperlocomotion but not behavioral sensitization to methamphetamine in postpubertal rats. Psychopharmacology, 192(3), 303-316. https://doi.org/10.1007/s00213-007-0729-8

Adell, A., Jiménez-Sánchez, L., López-Gil, X., \& Romón, T. (2012). Is the acute NMDA receptor hypofunction a valid model of schizophrenia? Schizophrenia Bulletin, 38(1), 9-14. https://doi.org/10.1093/schbul/sbr133

Adhikari, A., Topiwala, M. A., \& Gordon, J. A. (2009). Synchronized activity between the ventral hippocampus and the medial prefrontal cortex during anxiety. https://doi.org/10.1016/j.neuron.2009.12.002

Adler, C. M., Goldberg, T. E., Malhotra, A. K., Pickar, D., \& Breier, A. (1998). Effects of ketamine on thought disorder, working memory, and semantic memory in healthy volunteers. Biological Psychiatry, 43(11), 811-816. https://doi.org/10.1016/S00063223(97)00556-8

Ae, W. B. H., Vertes, R. P., Hoover, W. B., \& Vertes, R. P. (2007). Anatomical analysis of afferent projections to the medial prefrontal cortex in the rat. Brain Structure and Function, 212(2), 149-179. https://doi.org/10.1007/s00429-007-0150-4

Antonoudiou, P., Tan, Y. L., Kontou, G., Upton, A. L., \& Mann, E. O. (2020). Parvalbumin and Somatostatin Interneurons Contribute to the Generation of Hippocampal Gamma Oscillations. The Journal of Neuroscience, 40(40), 7668. https://doi.org/10.1523/JNEUROSCI.0261-20.2020

Ban, T. A. (2007). Fifty years chlorpromazine: A historical perspective. In Neuropsychiatric Disease and Treatment (Vol. 3, Issue 4, pp. 495-500). Dove Press. /pmc/articles/PMC2655089/

Belforte, J. E., Zsiros, V., Sklar, E. R., Jiang, Z., Yu, G., Li, Y., Quinlan, E. M., \& Nakazawa, K. (2010). Postnatal NMDA receptor ablation in corticolimbic 
interneurons confers schizophrenia-like phenotypes. Nature Neuroscience, 13(1), 76-83. https://doi.org/10.1038/nn.2447

Beneyto, M., \& Meador-Woodruff, J. H. (2008). Lamina-specific abnormalities of NMDA receptor-associated postsynaptic protein transcripts in the prefrontal cortex in schizophrenia and bipolar disorder. Neuropsychopharmacology, 33(9), 21752186. https://doi.org/10.1038/sj.npp.1301604

Bokil, H., Andrews, P., Kulkarni, J. E., Mehta, S., \& Mitra, P. (2010). Chronux: A Platform for Analyzing Neural Signals. Journal of Neuroscience Methods, 192(1), 146. https://doi.org/10.1016/J.JNEUMETH.2010.06.020

Braff, D. L., Geyer, M. A., \& Swerdlow, N. R. (2001). Human studies of prepulse inhibition of startle: Normal subjects, patient groups, and pharmacological studies. In Psychopharmacology (Vol. 156, Issues 2-3, pp. 234-258). https://doi.org/10.1007/s002130100810

Brotons-Mas, J. R., Montejo, N., O’Mara, S. M. S. M., \& Sanchez-Vives, M. V. M. V. (2010). Stability of subicular place fields across multiple light and dark transitions. European Journal of Neuroscience, 32(4), 648-658. https://doi.org/10.1111/j.1460-9568.2010.07308.x

Brotons-Mas, J. R. R., Schaffelhofer, S., Guger, C., O’Mara, S. M. M., \& SanchezVives, M. V. V. (2017). No Title. Neuroscience, 343, 174-189. https://doi.org/10.1016/j.neuroscience.2016.11.042

Buzsáki, G., Buhl, D. L., Harris, K. D., Csicsvari, J., Czéh, B., \& Morozov, A. (2003). Hippocampal network patterns of activity in the mouse. Neuroscience, 116(1), 201-211. https://doi.org/10.1016/S0306-4522(02)00669-3

Buzsáki, György, \& Watson, B. O. (2012). Brain rhythms and neural syntax: Implications for efficient coding of cognitive content and neuropsychiatric disease. Dialogues in Clinical Neuroscience, 14(4), 345-367. https://doi.org/10.31887/dcns.2012.14.4/gbuzsaki

Bygrave, A. M., Masiulis, S., Nicholson, E., Berkemann, M., Barkus, C., Sprengel, R., Harrison, P. J., Kullmann, D. M., Bannerman, D. M., \& Kätzel, D. (2016). Knockout of NMDA-receptors from parvalbumin interneurons sensitizes to schizophreniarelated deficits induced by MK-801. Translational Psychiatry, 6(4). https://doi.org/10.1038/tp.2016.44

Callicott, J. H., Bertolino, A., Mattay, V. S., Langheim, F. J. P., Duyn, J., Coppola, R., 
Goldberg, T. E., \& Weinberger, D. R. (2000). Physiological dysfunction of the dorsolateral prefrontal cortex in schizophrenia revisited. Cerebral Cortex, 10(11), 1078-1092. https://doi.org/10.1093/cercor/10.11.1078

Carlén, M., Meletis, K., Siegle, J. H., Cardin, J. A., Futai, K., Vierling-Claassen, D., Rühlmann, C., Jones, S. R., Deisseroth, K., Sheng, M., Moore, C. I., \& Tsai, L. H. (2012). A critical role for NMDA receptors in parvalbumin interneurons for gamma rhythm induction and behavior. Molecular Psychiatry, 17(5), 537-548. https://doi.org/10.1038/mp.2011.31

Chen, Z., Resnik, E., McFarland, J. M., Sakmann, B., \& Mehta, M. R. (2011). Speed Controls the Amplitude and Timing of the Hippocampal Gamma Rhythm. PLOS ONE, 6(6), e21408. https://doi.org/10.1371/JOURNAL.PONE.0021408

Del Arco, A., Segovia, G., \& Mora, F. (2008). Blockade of NMDA receptors in the prefrontal cortex increases dopamine and acetylcholine release in the nucleus accumbens and motor activity. Psychopharmacology, 201(3), 325-338. https://doi.org/10.1007/s00213-008-1288-3

Del Pino, I., Brotons-Mas, J. R., Marques-Smith, A., Marighetto, A., Frick, A., Marín, O., \& Rico, B. (2017). Abnormal wiring of $\mathrm{CCK}^{+}$basket cells disrupts spatial information coding. Nature Neuroscience, 20(6), 784-792.

https://doi.org/10.1038/nn.4544

delPino, I., García-Frigola, C., Dehorter, N., Brotons-Mas, J. R., Alvarez-Salvado, E., MartínezdeLagrán, M., Ciceri, G., Gabaldón, M. V., Moratal, D., Dierssen, M., Canals, S., Marín, O., \& Rico, B. (2013). Erbb4 Deletion from Fast-Spiking Interneurons Causes Schizophrenia-like Phenotypes. Neuron, 79(6), 1152-1168. https://doi.org/10.1016/j.neuron.2013.07.010

Eyjolfsson, E. M., Brenner, E., Kondziella, D., \& Sonnewald, U. (2006). Repeated injection of MK801: An animal model of schizophrenia? Neurochemistry International, 48(6-7), 541-546. https://doi.org/10.1016/j.neuint.2005.11.019

Hakami, T., Jones, N. C., Tolmacheva, E. A., Gaudias, J., Chaumont, J., Salzberg, M., O’Brien, T. J., \& Pinault, D. (2009). No Title. PLoS ONE, 4(8). https://doi.org/10.1371/journal.pone.0006755

Hargreaves, E. L., Côté, D., \& Shapiro, M. L. (1997). A dose of MK801 previously shown to impair spatial learning in the radial maze attenuates primed burst potentiation in the dentate gyrus of freely moving rats. Behavioral Neuroscience, 
111(1), 35-48. https://doi.org/10.1037/0735-7044.111.1.35

Harvey, P. D., Koren, D., Reichenberg, A., \& Bowie, C. R. (2006). Negative symptoms and cognitive deficits: What is the nature of their relationship? Schizophrenia Bulletin, 32(2), 250-258. https://doi.org/10.1093/SCHBUL/SBJ011

Hertzman, M., Reba, R. C., \& Kotlyarov, E. V. (1990). Single photon emission computed tomography in phencyclidine and related drug abuse. In American Journal of Psychiatry (Vol. 147, Issue 2, pp. 255-256). https://doi.org/10.1176/ajp.147.2.255b

Homayoun, H., \& Moghaddam, B. (2007). NMDA receptor hypofunction produces opposite effects on prefrontal cortex interneurons and pyramidal neurons. Journal of Neuroscience, 27(43), 11496-11500. https://doi.org/10.1523/JNEUROSCI.2213-07.2007

Hudson MR., okolenkoa E., O'Brien TJ.., Jones NC. NMDA receptors on parvalbuminpositive interneurons and pyramidal neurons both contribute to MK-801 induced gamma oscillatory disturbances: Complex relationships with behaviour, 134 Neurobiology of Disease 104625 (2020). https://doi.org/10.1016/j.nbd.2019.104625

Ibarz, J. M., Foffani, G., Cid, E., Inostroza, M., \& Prida, L. M. de la. (2010). Emergent Dynamics of Fast Ripples in the Epileptic Hippocampus. Journal of Neuroscience, 30(48), 16249-16261. https://doi.org/10.1523/JNEUROSCI.3357-10.2010

Inostroza, M., Brotons-Mas, J. R., Laurent, F., Cid, E., \& de la Prida, L. M. (2013). Specific impairment of "What-Where-When" episodic-like memory in experimental models of temporal lobe epilepsy. Journal of Neuroscience, 33(45), 17749-17762. https://doi.org/10.1523/JNEUROSCI.0957-13.2013

Jackson, M. E., Homayoun, H., \& Moghaddam, B. (2004). NMDA receptor hypofunction produces concomitant firing rate potentiation and burst activity reduction in the prefrontal cortex. www.pnas.orgcgidoi10.1073pnas.0308455101

James, S. L., Abate, D., Abate, K. H., Abay, S. M., Abbafati, C., Abbasi, N., Abbastabar, H., Abd-Allah, F., Abdela, J., Abdelalim, A., Abdollahpour, I., Abdulkader, R. S., Abebe, Z., Abera, S. F., Abil, O. Z., Abraha, H. N., AbuRaddad, L. J., Abu-Rmeileh, N. M. E., Accrombessi, M. M. K., ... Murray, C. J. L. (2018). Global, regional, and national incidence, prevalence, and years lived with disability for 354 Diseases and Injuries for 195 countries and territories, 1990- 
2017: A systematic analysis for the Global Burden of Disease Study 2017. The Lancet, 392(10159), 1789-1858. https://doi.org/10.1016/S0140-6736(18)32279-7

Jodo, E. (2013). The role of the hippocampo-prefrontal cortex system in phencyclidineinduced psychosis: A model for schizophrenia. In Journal of Physiology Paris (Vol. 107, Issue 6, pp. 434-440). Elsevier. https://doi.org/10.1016/j.jphysparis.2013.06.002

Jones, M. W., \& Wilson, M. A. (2005). Theta rhythms coordinate hippocampalprefrontal interactions in a spatial memory task. PLoS Biology, 3(12), 1-13. https://doi.org/10.1371/journal.pbio.0030402

Kirkpatrick, B., Fenton, W. S., Carpenter, W. T., Jr., \& Marder, S. R. (2006). The NIMHMATRICS Consensus Statement on Negative Symptoms. Schizophrenia Bulletin, 32(2), 214. https://doi.org/10.1093/SCHBUL/SBJ053

Kiss, T., Feng, J., Hoffmann, W. E., Shaffer, C. L., \& Hajós, M. (2013). Rhythmic theta and delta activity of cortical and hippocampal neuronal networks in genetically or pharmacologically induced $\mathrm{N}$-methyl-d-aspartate receptor hypofunction under urethane anesthesia. Neuroscience, 237, 255-267. https://doi.org/10.1016/j.neuroscience.2013.01.058

Kittelberger, K., Hur, E. E., Sazegar, S., Keshavan, V., \& Kocsis, B. (2012). Comparison of the effects of acute and chronic administration of ketamine on hippocampal oscillations: Relevance for the NMDA receptor hypofunction model of schizophrenia. Brain Structure and Function, 217(2), 395-409. https://doi.org/10.1007/s00429-011-0351-8

Korotkova, T., Fuchs, E. C., Ponomarenko, A., von Engelhardt, J., \& Monyer, H. (2010). NMDA Receptor Ablation on Parvalbumin-Positive Interneurons Impairs Hippocampal Synchrony, Spatial Representations, and Working Memory. Neuron, 68(3), 557-569. https://doi.org/10.1016/j.neuron.2010.09.017

Kristiansen, L. V., Beneyto, M., Haroutunian, V., \& Meador-Woodruff, J. H. (2006). Changes in NMDA receptor subunits and interacting PSD proteins in dorsolateral prefrontal and anterior cingulate cortex indicate abnormal regional expression in schizophrenia. Molecular Psychiatry, 11(8), 737-747. https://doi.org/10.1038/sj.mp.4001844

Kropff, E., Carmichael, J. E., Moser, E. I., \& Moser, M. B. (2021). Frequency of theta rhythm is controlled by acceleration, but not speed, in running rats. Neuron, 
109(6), 1029-1039.e8. https://doi.org/10.1016/J.NEURON.2021.01.017

Lee, J., Hudson, M. R., O’Brien, T. J., Nithianantharajah, J., \& Jones, N. C. (2017). Local NMDA receptor hypofunction evokes generalized effects on gamma and high-frequency oscillations and behavior. Neuroscience, 358, 124-136. https://doi.org/10.1016/j.neuroscience.2017.06.039

Lewis, D. A. (2012). No Title. European Journal of Neuroscience, 35(12), 1871-1878. https://doi.org/10.1111/j.1460-9568.2012.08156.x

Long, L. L., Hinman, J. R., Chen, C. M., Escabi, M. A., \& Chrobak, J. J. (2014). Theta dynamics in rat: Speed and acceleration across the septotemporal axis. PLoS ONE, 9(5). https://doi.org/10.1371/journal.pone.0097987

López-Gil, X., Babot, Z., Amargós-Bosch, M., Suñol, C., Artigas, F., \& Adell, A. (2007). Clozapine and haloperidol differently suppress the MK-801-increased glutamatergic and serotonergic transmission in the medial prefrontal cortex of the rat. Neuropsychopharmacology, 32(10), 2087-2097.

https://doi.org/10.1038/sj.npp.1301356

Lopez-Pigozzi, D., Laurent, F., Brotons-Mas, J. R., Valderrama, M., Valero, M., Fernandez-Lamo, I., Cid, E., Gomez-Dominguez, D., Gall, B., \& de la Prida, L. M. (2016). Altered oscillatory dynamics of CA1 parvalbumin basket cells during thetagamma rhythmopathies of temporal lobe epilepsy. ENeuro, 3(6), 1-20. https://doi.org/10.1523/ENEURO.0284-16.2016

Malhotra, A. K., Pinals, D. A., Adler, C. M., Elman, I., Clifton, A., Pickar, D., \& Breier, A. (1997). Ketamine-induced exacerbation of psychotic symptoms and cognitive impairment in neuroleptic-free schizophrenics. Neuropsychopharmacology, 17(3), 141-150. https://doi.org/10.1016/S0893-133X(97)00036-5

Meltzer, H. Y., \& Stahl, S. M. (1976). The dopamine hypothesis of schizophrenia: a review. Schizophr Bull . 1976;2(1):19-76. doi: 10.1093/schbul/2.1.19.

Mena, A., Ruiz-Salas, J. C., Puentes, A., Dorado, I., Ruiz-Veguilla, M., \& De la Casa, L. G. (2016). Reduced prepulse inhibition as a biomarker of schizophrenia. Frontiers in Behavioral Neuroscience, 10(OCT), 202. https://doi.org/10.3389/fnbeh.2016.00202

Miedel, C. J., Patton, J. M., Miedel, A. N., Miedel, E. S., \& Levenson, J. M. (2017). Assessment of spontaneous alternation, novel object recognition and limb clasping in transgenic mouse models of amyloid- $\beta$ and tau neuropathology. 
Journal of Visualized Experiments, 2017(123), 55523.

https://doi.org/10.3791/55523

Moghaddam, B., \& Javitt, D. (2012). From revolution to evolution: The glutamate hypothesis of schizophrenia and its implication for treatment. In

Neuropsychopharmacology (Vol. 37, Issue 1, pp. 4-15). Nature Publishing Group. https://doi.org/10.1038/npp.2011.181

Monyer, H., Burnashev, N., Laurie, D. J., Sakmann, B., \& Seeburg, P. H. (1994).

Developmental and regional expression in the rat brain and functional properties of four NMDA receptors. Neuron, 12(3), 529-540. https://doi.org/10.1016/08966273(94)90210-0

Murillo, A., Navarro, A. I., Puelles, E., Zhang, Y., Petros, T. J., \& Pérez-Otaño, I. (2021). Temporal Dynamics and Neuronal Specificity of Grin3a Expression in the Mouse Forebrain. Cerebral Cortex (New York, N.Y. : 1991), 31(4), 1914-1926. https://doi.org/10.1093/cercor/bhaa330

Neuropathological Background of MK-801 for Inducing Murine Model of Schizophrenia, Psychiatry and Neuroscience Update - Vol. II pp 337-354337 (2017). https://doi.org/10.1007/978-3-319-53126-7_25

Navas-Olive, A., Valero, M., Jurado-Parras, T., de Salas-Quiroga, A., Averkin, R. G., Gambino, G., Cid, E., \& de la Prida, L. M. (2020). Multimodal determinants of phase-locked dynamics across deep-superficial hippocampal sublayers during theta oscillations. Nature Communications, 11(1). https://doi.org/10.1038/s41467020-15840-6

Olney, J. W., Newcomer, J. W., \& Farber, N. B. (1999). NMDA receptor hypofunction model of schizophrenia. Journal of Psychiatric Research, 33(6), 523-533. https://doi.org/10.1016/S0022-3956(99)00029-1

Olszewski, M., Dolowa, W., Matulewicz, P., Kasicki, S., \& Hunt, M. J. (2013). NMDA receptor antagonist-enhanced high frequency oscillations: Are they generated broadly or regionally specific? European Neuropsychopharmacology, 23(12), 1795-1805. https://doi.org/10.1016/j.euroneuro.2013.01.012

Owen, M. J., Sawa, A., \& Mortensen, P. B. (2016). Schizophrenia. In The Lancet (Vol. 388, Issue 10039, pp. 86-97). Lancet Publishing Group. https://doi.org/10.1016/S0140-6736(15)01121-6

Pérez-Otaño I., Larsen RS., Wesseling JW. Emerging roles of GluN3-containing NMDA 
receptors in the CNS. Nat Rev Neurosci . 2016 Oct;17(10):623-35. doi: 10.1038/nrn.2016.92.

Richard, G. R., Titiz, A., Tyler, A., Holmes, G. L., Scott, R. C., \& Lenck-Santini, P.-P. (2013). Speed Modulation of Hippocampal Theta Frequency Correlates With Spatial Memory Performance. https://doi.org/10.1002/hipo.22164

Royer, S., Zemelman, B. V, Losonczy, A., Kim, J., Chance, F., Magee, J. C., \& Buzsáki, G. (2012). Control of timing, rate and bursts of hippocampal place cells by dendritic and somatic inhibition. Nature Neuroscience, 15(5), 769. https://doi.org/10.1038/NN.3077

Sigurdsson, T., \& Duvarci, S. (2016). Hippocampal-prefrontal interactions in cognition, behavior and psychiatric disease. In Frontiers in Systems Neuroscience (Vol. 9, Issue JAN2016). Frontiers Research Foundation. https://doi.org/10.3389/fnsys.2015.00190

Sigurdsson, T., Stark, K. L., Karayiorgou, M., Gogos, J. A., \& Gordon, J. A. (2010). Impaired hippocampal-prefrontal synchrony in a genetic mouse model of schizophrenia. Nature, 464(7289), 763-767. https://doi.org/10.1038/nature08855

Tamura, M., Spellman, T. J., Rosen, A. M., Gogos, J. A., \& Gordon, J. A. (2017). Hippocampal-prefrontal theta-gamma coupling during performance of a spatial working memory task. Nature Communications, 8(1). https://doi.org/10.1038/s41467-017-02108-9

Terrazas, A., Krause, M., Lipa, P., Gothard, K. M., Barnes, C. A., \& McNaughton, B. L. (2005). Self-Motion and the Hippocampal Spatial Metric. Journal of Neuroscience, 25(35), 8085-8096. https://doi.org/10.1523/JNEUROSCI.0693-05.2005

Uhlhaas, P. J., \& Singer, W. (2010). Abnormal neural oscillations and synchrony in schizophrenia. In Nature Reviews Neuroscience (Vol. 11, Issue 2, pp. 100-113). Nature Publishing Group. https://doi.org/10.1038/nrn2774

Valero, M., \& de la Prida, L. M. (2018). The hippocampus in depth: a sublayer-specific perspective of entorhinal-hippocampal function. In Current Opinion in Neurobiology (Vol. 52, pp. 107-114). Elsevier Ltd. https://doi.org/10.1016/j.conb.2018.04.013

Vollenweider, F. X., Vontobel, P., Øye, I., Hell, D., \& Leenders, K. L. (2000). Effects of (S)-ketamine on striatal dopamine: A [11C]raclopride PET study of a model psychosis in humans. Journal of Psychiatric Research, 34(1), 35-43. 
https://doi.org/10.1016/S0022-3956(99)00031-X

von Engelhardt, J., Bocklisch, C., Tönges, L., Herb, A., Mishina, M., \& Monyer, H. (2015). GluN2D-containing NMDA receptors-mediate synaptic currents in hippocampal interneurons and pyramidal cells in juvenile mice. Frontiers in Cellular Neuroscience, 9(March), 1-16. https://doi.org/10.3389/fncel.2015.00095

Wȩdzony, K., Klimek, V., \& Goembiowska, K. (1993). MK-801 elevates the etracellular concentration of dopamine in the rat prefrontal cortex and increases the density of striatal dopamine D1 receptors. Brain Research, 622(1-2), 325-329. https://doi.org/10.1016/0006-8993(93)90839-F

Weickert, C. S., Fung, S. J., Catts, V. S., Schofield, P. R., Allen, K. M., Moore, L. T., Newell, K. A., Pellen, D., Huang, X. F., Catts, S. V., \& Weickert, T. W. (2013). Molecular evidence of $\mathrm{N}$-methyl-D-aspartate receptor hypofunction in schizophrenia. Molecular Psychiatry, 18(11), 1185-1192. https://doi.org/10.1038/mp.2012.137

Weickert, T. W., Goldberg, T. E., Gold, J. M., Bigelow, L. B., Egan, M. F., \& Weinberger, D. R. (2000). Cognitive impairments in patients with schizophrenia displaying preserved and compromised intellect. Archives of General Psychiatry, 57(9), 907-913. https://doi.org/10.1001/archpsyc.57.9.907

Whishaw, I. Q., \& Vanderwolf, C. H. (1973). Hippocampal EEG and behavior: Change in amplitude and frequency of RSA (Theta rhythm) associated with spontaneous and learned movement patterns in rats and cats. Behavioral Biology, 8(4), 461484. https://doi.org/10.1016/S0091-6773(73)80041-0

Young, C. K., Ruan, M., \& McNaughton, N. (2020). Speed modulation of hippocampal theta frequency and power predicts water maze learning. BioRxiv, 2020.03.31.016907. https://doi.org/10.1101/2020.03.31.016907 


\section{Supplementary}

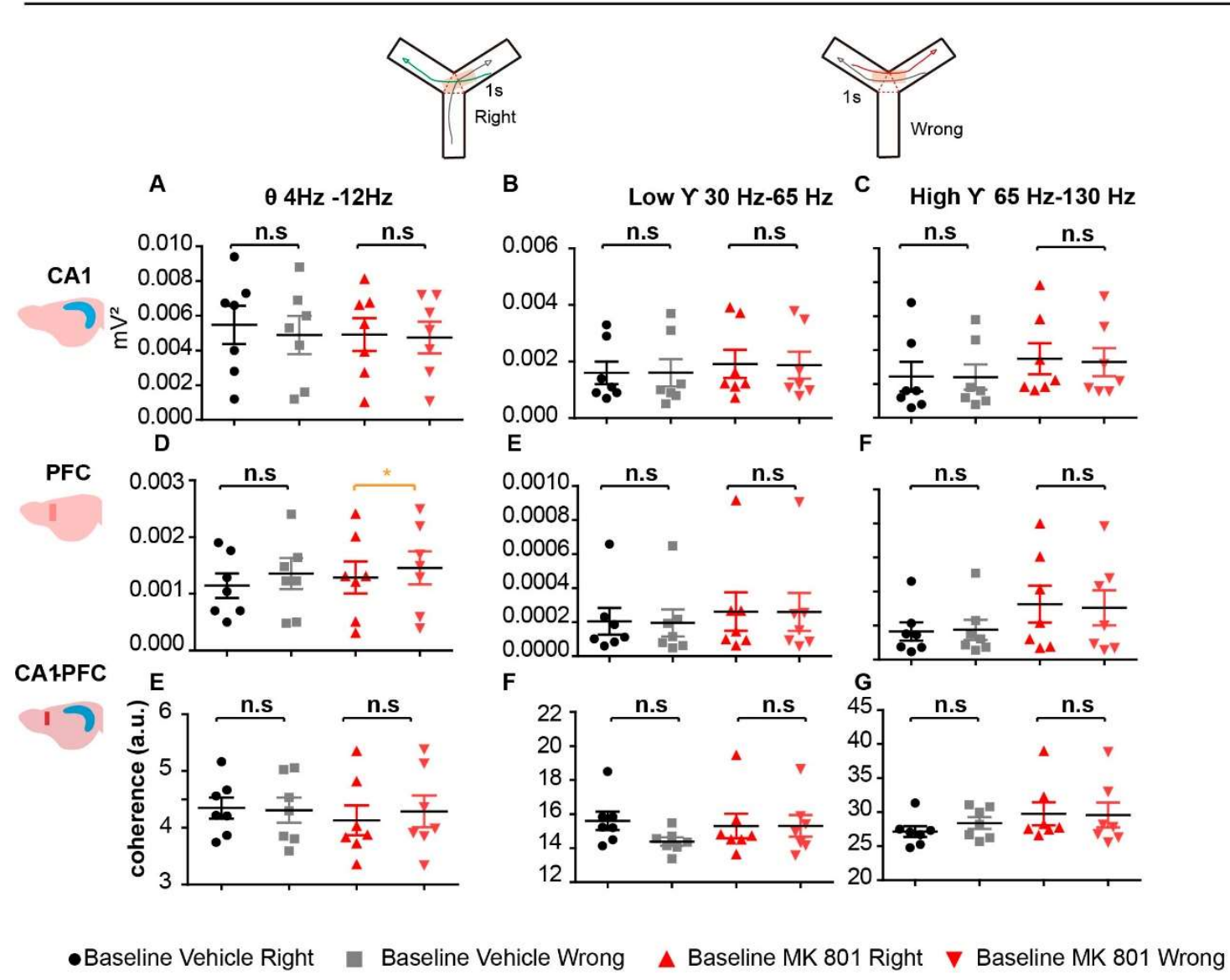

Figure S1. A. Hippocampal theta activity was significantly higher during right vs wrong trials in the baseline condition. $B$ and $C$. No changes in low and high gamma were found. D, E, and F. No changes in oscillatory power were found in the PFC. E, F, and G. Similarly, no changes in coherence were found. 

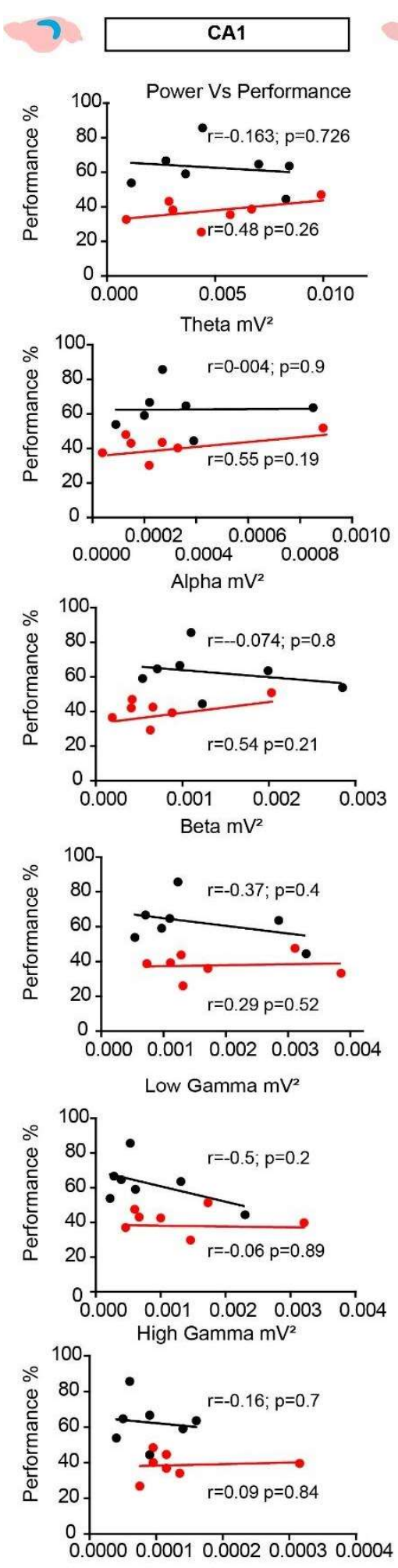

HFO $\mathrm{mV}^{2}$
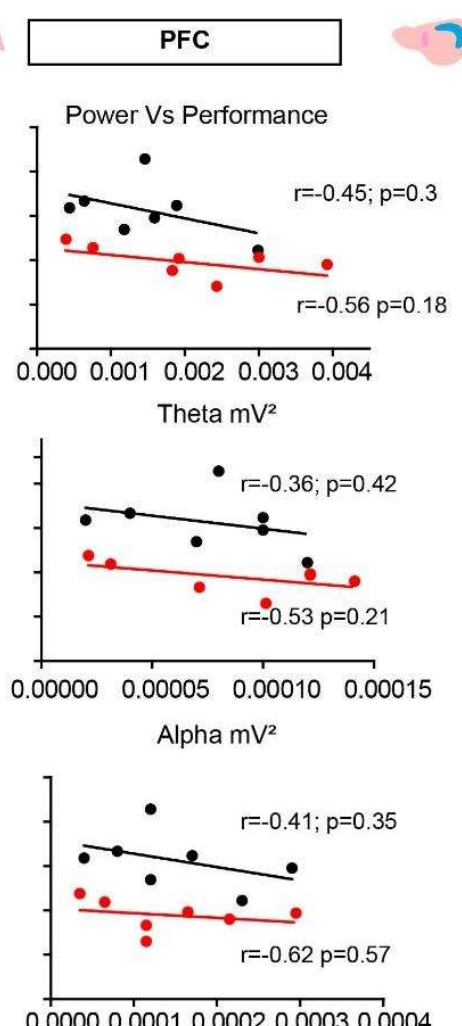

0.00000 .00010 .00020 .00030 .0004

Beta $\mathrm{mV}^{2}$
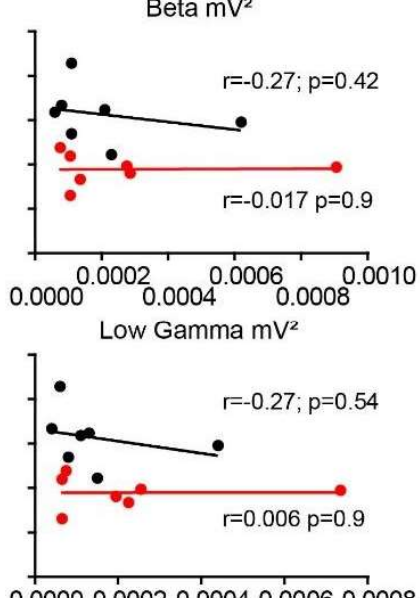

0.00000 .00020 .00040 .00060 .0008 High Gamma mV²

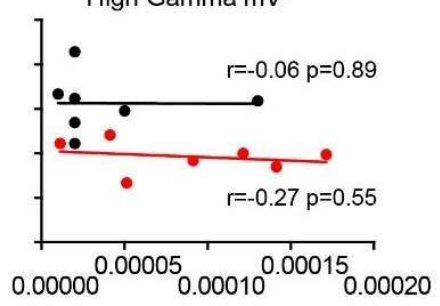

$\mathrm{HFO} \mathrm{mV}^{2}$
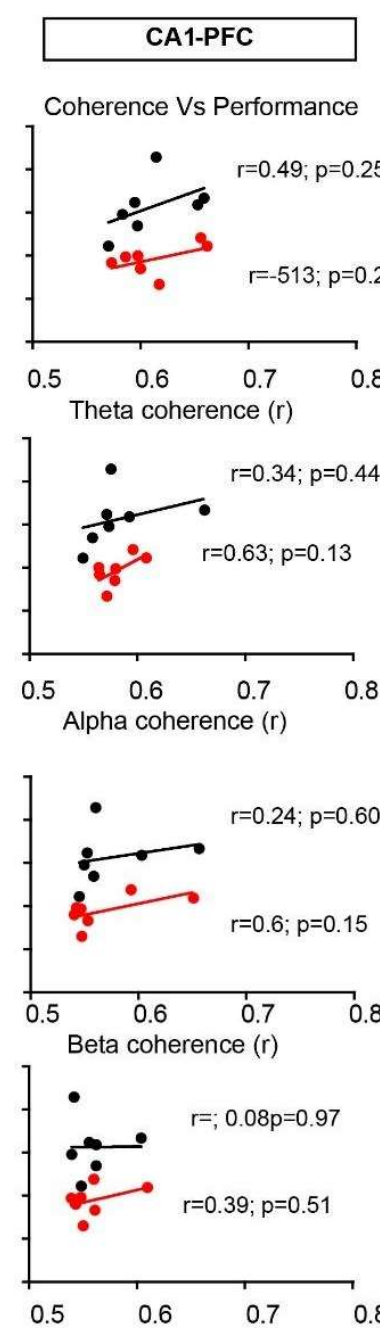

Low gamma coherence $(r)$

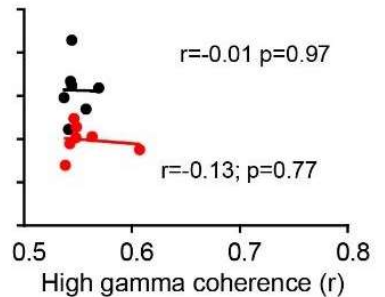

High gamma coherence $(r)$

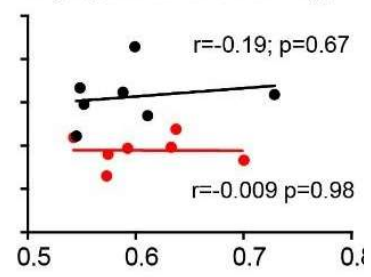

HFO coherence ( $r$ )

Figure S2. Mean power values for the different oscillatory bands and coherence were not correlated with performance in the y-maze. 


\section{Abad et al}

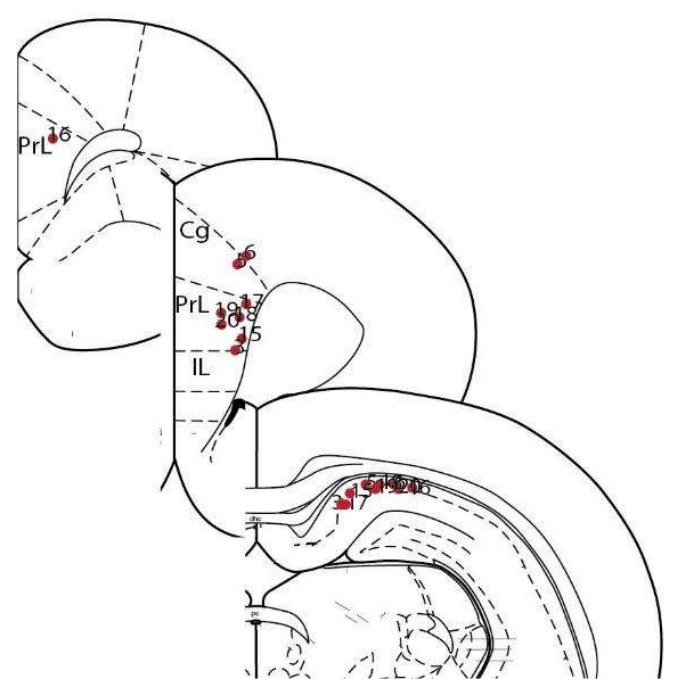

Figure S3. Approximated location of electrode positions. Electrodes were implanted in CA1 (AP: -2-2.5, M-L:1.2 V: $0.6 \mathrm{~mm}$ ) and PFC (AP: 1-2, M-L:0.5-1, V: 1.2-1.9 mm). Electrode recording sites were obtained from anatomical analysis and implanting coordinates. In the case of two animals, the electrode location was inferred uniquely from implant coordinates. 